\title{
Principles and Techniques of Exodontia
}

\author{
Anuj Jain
}

\subsection{Introduction}

Exodontia is the removal of tooth from its socket in the alveolar bone with the help of anesthesia. It is a challenging procedure in itself as the dental surgeon has to work in an oral cavity, access to which is restricted by patient's lips and cheeks. Also, the movement of the tongue and the jaw makes the procedure troublesome. Another factor which complicates the procedure is saliva. The oral cavity communicates with the pharynx which further communicates into larynx and esophagus, due to which there is always a potential risk of aspiration or deglutition of the extracted tooth. Hence, it is of paramount importance that the exodontia must be performed judiciously and be based on sound surgical principles.

Apart from the competence and practical skills of the dental surgeon, patient's cooperation also holds the key to an uneventful extraction of a tooth. Patient's cooperation is dependent on various factors like misinformation, myths, anxiety, pain phobia, patient's previous exodontia experiences, and trust over the operator. A dental surgeon must have a calm, patient, and reassuring approach towards the patient to gain his/her confidence. This empathetic nature of the doctor must be superadded with good principles of patient management and pharmacokinetics. This combination helps in controlling patient's anxiety and fear toward the procedure.

\subsection{Definition}

Exodontia or tooth extraction is defined as the painless removal of a whole tooth or tooth root, with minimal trauma to the investing tissues, so that the bone heals uneventfully and no postoperative prosthetic problem is created [1].

\footnotetext{
A. Jain $(\bowtie)$

Oral and Maxillofacial Surgeon, Department of Trauma and Emergency Medicine, All India Institute of Medical Sciences, Bhopal, Madhya Pradesh, India
}

\subsection{History}

The thought of how extractions were performed in eleventh century is disturbing. The operator used to hold the patient's head between his knees, the soft tissue was cut with a sharp scalpel, and the tooth was pulled out in single direction. Often the wound was cauterized with a red hot iron and a repellent mouthwash was prescribed [2].

Historically, dental extractions were carried out as a prophylactic as well as therapeutic treatment for a variety of illnesses. Before the discovery of antibiotics, exodontia was a preferred treatment. Dentistry was not a separate profession at that time and mainly the barbers were extracting the tooth popularly known as 'barber surgeons'. They used to hang rows of rotten teeth outside their shops to advertise their services as tooth pullers [3].

Various kinds of instruments were used in different geographical areas of the globe and can be grouped as forceps, pelicans, keys, screws, and elevators. The modern-day forceps have been evolved over time and are highlighted in Table 13.1.

Regarding Indian history, Sushruta is to be credited for his description of surgical instruments. He highlighted two types of instruments viz. 'Yantra or blunt' and 'Shastra or sharp'. And among the category yantra, 'dantasanka' - a special forceps for extraction of teeth is described [6]. Vagbhata, around $650 \mathrm{AD}$, described forceps for extraction of tooth [7].

\subsection{Applied Surgical Anatomy}

\section{Knowledge of Anatomy is the foundation for an uneventful} surgery.

The jaw bones namely maxilla and mandible harbor the teeth in their respective alveolar process within the shapeappropriate sockets designed by nature. Sharpey's fibers of periodontal ligament attach the teeth to their alveolar sockets with the joint called gomphosis. 
Table 13.1 Evolution of dental forceps

1 Seventeenth It can be assumed that extractions were carried out considering the prominent carvings of forceps on the walls of Century BC $\quad$ Egyptian caves in the work of Edwin Smith Papyrus [4].

2 Fifth century BC Hippocrates referred that the dental forceps have been discovered in Greece. These forceps were made up of Iron and called 'Odontagra' [4].

3 Fourteenth century Guy de Chauliac invented pelicans for dental extraction. They were named after the bird from their resemblance to the shape of the beak. The early drawing of the pelican showed a straight shaft, a wheel-shaped bolster, and a single claw attached to the shaft by a rivet [2].

4 Sixteenth century Pierre Fauchard, 'father of modern dentistry', modified the pelican with proper dimensions and advised regarding patient and operator position. His pelican was double hooked and held the tooth firmly, following which 'shaking' of tooth was done to achieve extraction [5].

5 Eighteenth century Dental key (also known as clef de Garengeot, fothergill key), an instrument modeled after a door was popular. It was first inserted horizontally into the mouth, then its claw would be tightened over the tooth to be extracted. Once secured, rotation movements were carried out to loosen the tooth. It was continuously modified for better results; however, its use was often associated with complications [2].

6 By the end of the The introduction of modern-day forceps was made popular notably by sir John tomes making the dental key nineteenth century obsolete [2].

\subsubsection{Maxilla (Fig. 13.1)}

It is a paired bone forming the midface of a person, bearing upper teeth separating the oral cavity from the nasal cavity and maxillary sinuses. Compared to the mandible, it is composed of spongier bone with thinner cortical plates. Palatal processes extend from both the maxillary bone and meet in the midline to form the roof of the oral cavity. The branches of Maxillary Nerve innervate the maxillary teeth and their periodontium (Table 13.2).

Exodontia becomes easier in maxilla due to following reasons:

1. The maxilla is characterized by thin cortical plates with spongier bone due to which the alveolar sockets expand easily on the application of pressure, facilitating extraction.

2. Due to thin cortical plates, mere para periosteal infiltrations of local anesthetic solutions produce adequate anesthesia to perform a dental extraction. However, in cases where adequate anesthesia is not achieved, a nerve block is desirable.

3. Maxilla has better vascularity as compared to mandible due to which the healing is faster with minimum complications.

Following factors complicate exodontia of maxillary teeth:

1. Use of heavy elevators is associated with the risk of fracture of the alveolar bone. Hence, their use must be judicious.

2. The root apices of maxillary molars are in close proximity to the floor of maxillary sinus with a thin bone separating them. Due to which there are chances of.

(a) Oroantral communication during the extraction of maxillary molars.

(b) Spread of periapical infection into the sinus leading to odontogenic maxillary sinusitis.

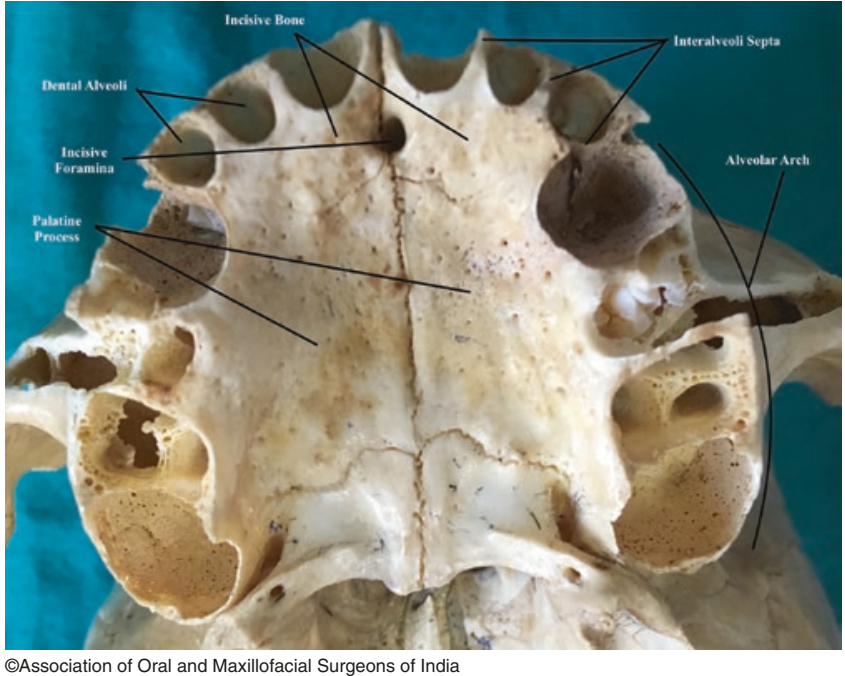

CAssociation of Oral and Maxillofacial Surgeons of India

Fig. 13.1 Alveolar process of maxilla

(c) Displacement of the root into maxillary sinus if injudicious retrieval is attempted in the event of a root fracture.

3. The maxillary third molar is present in the maxillary tuberosity as it is the last tooth to erupt. There are high chances of maxillary tuberosity fracture in patients with unfavorable and bizarre root patterns especially in the elderly as the tuberosity is made up of spongy bone.

\subsubsection{Mandible (Fig. 13.2)}

It is horseshoe shaped, mobile and the heaviest bone of the craniofacial skeleton. Compared to maxilla, it has less spongy bone as well as vascularity and has thick cortices. The branches of Mandibular Nerve innervate the mandibular teeth and their periodontium (Table 13.3). 
Table 13.2 Nerve supply of maxillary teeth with periodontal tissue

\begin{tabular}{|c|c|c|}
\hline Teeth & Nerve supply & Nerve blocks \\
\hline Central incisor & $\begin{array}{l}\text { ASAN: Tooth and its buccal soft tissue } \\
\text { Anastomosis with opposite side } \\
\text { NPN: Palatal soft tissue }\end{array}$ & $\begin{array}{l}\text { Infraorbital nerve block } \\
\text { Local infiltration on buccal aspect } \\
\text { Nasopalatine nerve block }\end{array}$ \\
\hline Lateral incisor and canine & $\begin{array}{l}\text { ASAN: Tooth and its buccal soft tissue } \\
\text { NPN: Palatal soft tissue }\end{array}$ & $\begin{array}{l}\text { Infraorbital nerve block } \\
\text { Nasopalatine nerve block }\end{array}$ \\
\hline Premolars & $\begin{array}{l}\text { MSAN: Tooth and its buccal soft tissue } \\
\text { GPN: Palatal soft tissue }\end{array}$ & $\begin{array}{l}\text { Infraorbital nerve block } \\
\text { Greater palatine nerve block }\end{array}$ \\
\hline First molar & $\begin{array}{l}\text { MSAN: Mesiobuccal root } \\
\text { PSAN: Tooth and its buccal soft tissue } \\
\text { GPN: Palatal soft tissue }\end{array}$ & $\begin{array}{l}\text { Local infiltration on buccal aspect } \\
\text { Posterior superior alveolar nerve block } \\
\text { Greater palatine nerve block }\end{array}$ \\
\hline Second and third molar & $\begin{array}{l}\text { PSAN: Tooth and its buccal soft tissue } \\
\text { GPN: Palatal soft tissue }\end{array}$ & $\begin{array}{l}\text { Posterior superior alveolar nerve block } \\
\text { Greater palatine nerve block }\end{array}$ \\
\hline
\end{tabular}

Abbreviations: ASAN Anterior Superior Alveolar Nerve, NPN Nasopalatine Nerve, MSAN Middle Superior Alveolar Nerve, GPN Greater Palatine Nerve, PSAN Posterior Superior Alveolar Nerve

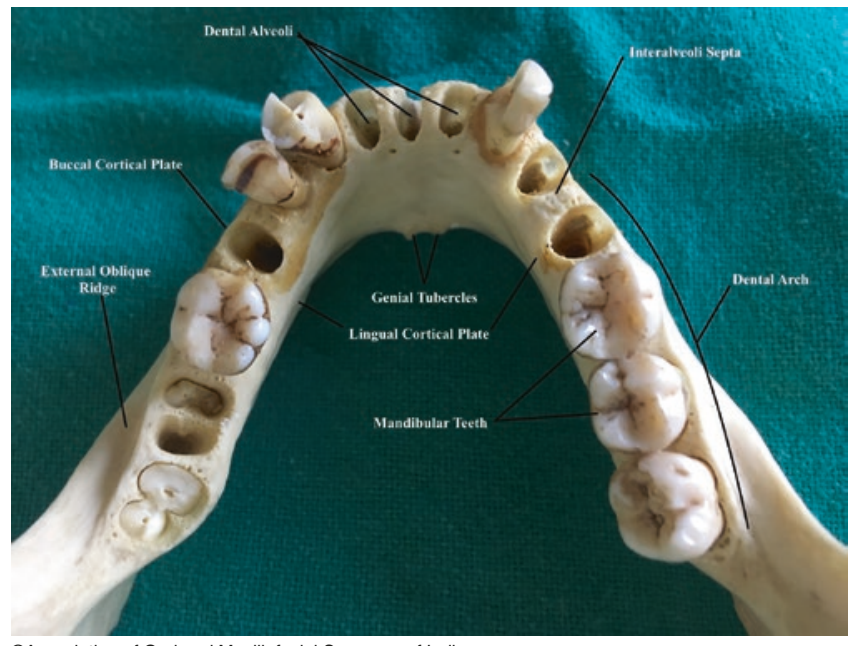

CAssociation of Oral and Maxillofacial Surgeons of India

Fig. 13.2 Alveolar process of mandible

Table 13.3 Nerve supply of mandibular teeth with periodontal tissue

\begin{tabular}{|c|c|c|}
\hline Teeth & Nerve supply & Nerve blocks \\
\hline $\begin{array}{l}\text { Incisors and } \\
\text { canine }\end{array}$ & $\begin{array}{l}\text { Inferior alveolar nerve: } \\
\text { Teeth } \\
\text { Mental nerve: Buccal soft } \\
\text { tissue } \\
\text { Lingual nerve: Lingual } \\
\text { soft tissue }\end{array}$ & $\begin{array}{l}\text { Inferior alveolar } \\
\text { nerve block } \\
\text { Mental nerve block } \\
\text { Lingual nerve block }\end{array}$ \\
\hline $\begin{array}{l}\text { Premolars and } \\
\text { molars }\end{array}$ & $\begin{array}{l}\text { Inferior alveolar nerve: } \\
\text { Teeth } \\
\text { Long Buccal nerve: } \\
\text { Buccal soft tissue } \\
\text { Lingual nerve: Lingual } \\
\text { soft tissue }\end{array}$ & $\begin{array}{l}\text { Inferior alveolar } \\
\text { nerve block } \\
\text { Long Buccal nerve } \\
\text { block } \\
\text { Lingual nerve block }\end{array}$ \\
\hline
\end{tabular}

Following factors complicate exodontia of mandibular teeth:

1. Presence of thick cortical plates makes it a requirement to apply more pressure for luxation and extraction of teeth as the sockets do not expand readily.

2. Due to less vascularity, healing is slower as compared to maxilla.

3. Mandible is depressed when the mouth is open. Hence, there are high chances of temporomandibular joint injury or dislocations if the mandible is unsupported with the application of forces in a long-standing procedure.

\subsubsection{Teeth}

Apart from the bone, the anatomy of teeth also plays a pivotal role in an uneventful extraction. The shape of crown and roots must be assessed carefully, preoperatively. A narrow tapering crown requires the use of a lighter beaked forceps whereas a bulbous crown needs to be extracted using heavy beaked forceps. If the tooth is multirooted, it offers more resistance than a single-rooted tooth and cannot be extracted using a rotational force, as such a motion will lead to root fracture. In cases where the roots are divergent, the application of heavy forces will lead to root fracture. Dilacerated roots are also prone to fracture on the application of injudicious forces. Also, a more careful approach is required while extracting non-vital and endodontically treated teeth, as they fracture readily due to their fragile and brittle nature secondary carious undermining and loss of pulpal tissue. 


\subsection{Indications for Exodontia}

Extraction of the teeth can be either prophylactic or therapeutic. Following are the indications for exodontia (Box 13.1).

1. Dental Caries: Extensively damaged teeth due to caries which cannot be preserved/restored by any conservative or endodontic procedure. (Fig. 13.3a).

2. Pulp Pathology: Pulpal necrosis or any pulpal pathology which cannot be treated by endodontic therapy (Fig. 13.3b).

3. Severe Periodontal Disease: Periodontally compromised teeth with mobility and irreparable loss of periodontal tissue (Fig. 13.3c).

4. Periapical Pathology: To prevent the spread of infection, in cases where all the reparative measures for periapical pathology have failed (Fig. 13.3d).

5. Orthodontic Reasons: There are a few conditions when a tooth is indicated for extraction during the course of orthodontic treatment.

(a) Malposed teeth: The teeth which are misaligned and cannot be reoriented within the proper arch form with orthodontic treatment.

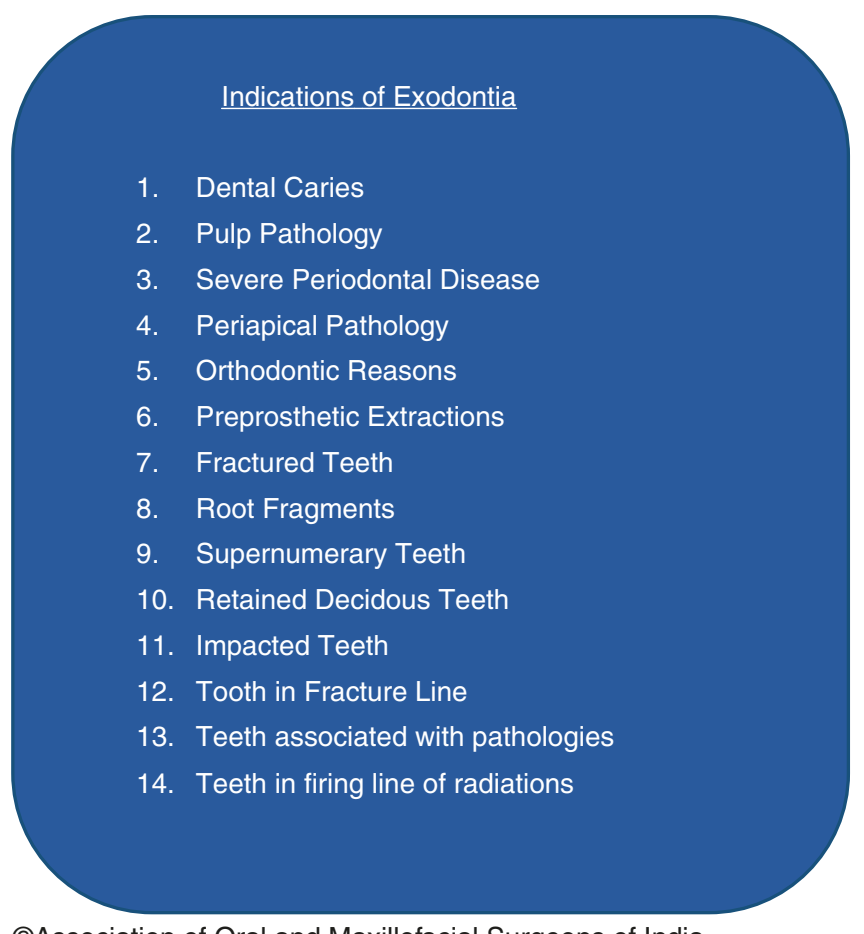

(CAssociation of Oral and Maxillofacial Surgeons of India

Box 13.1 Indications of exodontia (b) Creation of Space: To gain space to align malposed teeth. In such cases, premolars are commonly extracted.

(c) Serial Extractions: During the mixed dentition stage, a few deciduous teeth are extracted in a sequential manner to avoid malocclusion in permanent dentition as the child grows.

6. Preprosthetic Extractions: Total extraction for the fabrication of a complete denture or extraction of a few undesirable teeth to provide better design and stability to a removable partial denture.

7. Fractured Teeth: The teeth which are fractured and cannot be conserved (Fig. 13.3e).

8. Root Fragments: Root fragments which may cause various problems like recurrent ulcerations under a denture, initiation of bony pathologies, and numbness if in close proximity to nerve. However, considerably small asymptomatic root fragments may be left alone but the patient needs to be kept under regular follow-up (Fig. 13.3f).

9. Supernumerary Teeth: These teeth may be malposed or impacted. They predispose to malocclusion, pain, periodontal disturbance, pathologies, or sometimes esthetics. If there is no advantage in retaining a supernumerary tooth, it must be subjected to extraction (Fig. 13.3g).

10. Retained Decidous Teeth: Deciduous teeth which are retained beyond the age of exfoliation.

11. Impacted Teeth: Teeth impacted in the jaw and creating discomfort to the patient or identified incidentally and found to be initiating some pathological changes within the bone (Fig. 13.3h).

12. Tooth in fracture line (Fig. 13.3i): The extraction of tooth in fracture line has always been controversial. In earlier times, all the teeth in fracture line were extracted but in recent times a more conservative approach is advocated. The teeth in fracture line are indicated for extraction if the tooth is a source of infection at the site of the fracture, the tooth itself is fractured, or the retention of the tooth in fracture line may interfere with the fracture reduction or healing.

13. Teeth associated with pathologies (Fig. 13.3j): Teeth involved in cyst formation and associated with other pathologies like tumors, osteomyelitis, or neoplasms.

14. Teeth in firing line of radiations: In the past, prophylactic extractions were carried out before the patient was subjected to radiation therapy. This practice was done as the effects of radiation, such as loss of vascularity of bone and radiation caries of the tooth, leading to a risk of osteoradionecrosis. However, with betterment in technology, it is not commonly practiced anymore. 


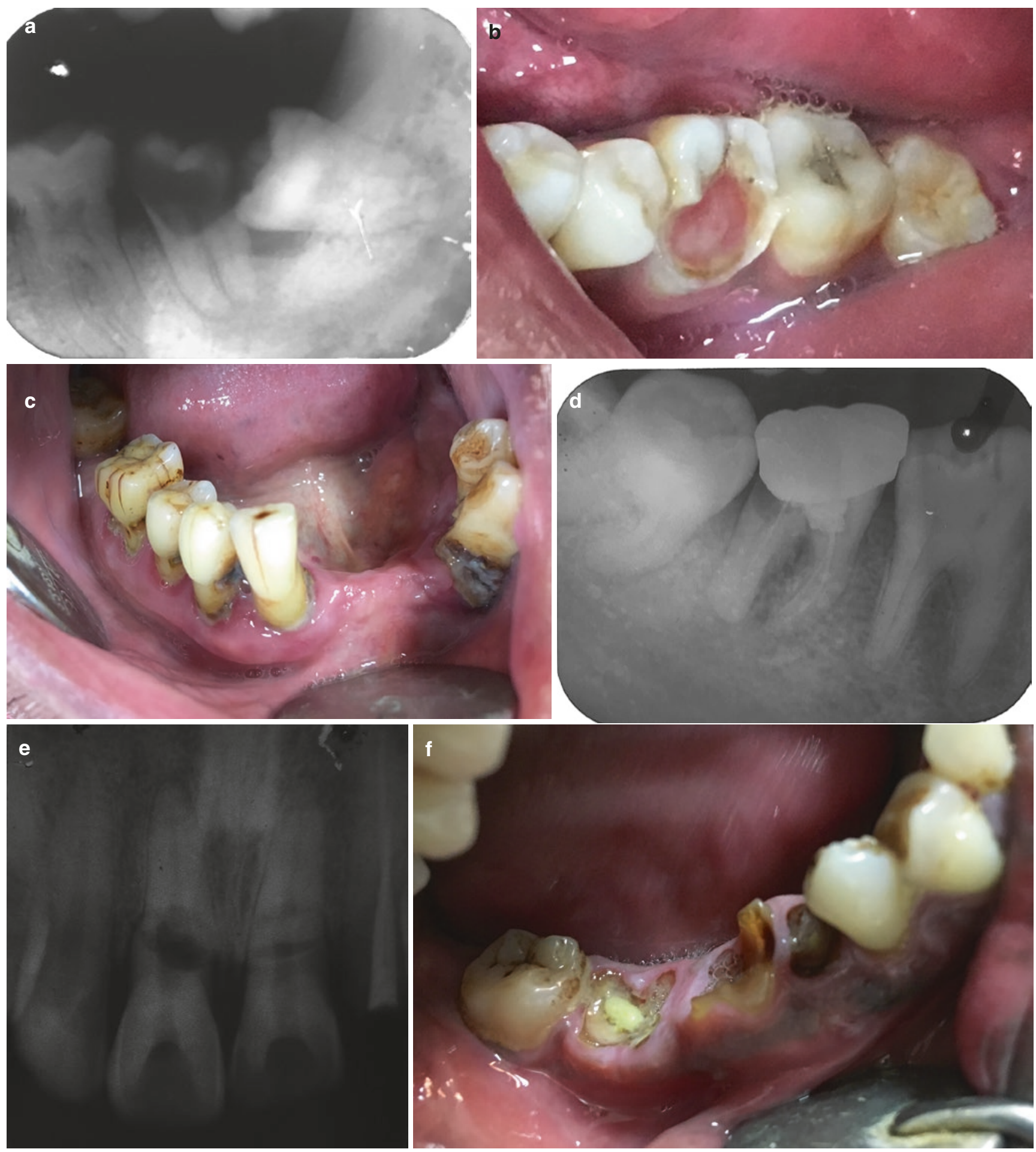

Fig. 13.3 (a) Intraoral periapical radiograph showing grossly carious second molar indicated for extraction. (b) Clinical Photograph showing pulpal pathology. (c) Clinical Photograph showing generalized periodontitis. (d) Radiograph showing developing root caries following endodontic treatment. (e) Radiograph showing fractured central inci- sors. (f) Clinical Photograph showing root pieces. (g) Clinical Photograph showing supernumerary teeth. (h) OPG showing impacted mandibular canine. (i) OPG showing left mandibular third molar in fracture line. (j) OPG showing cyst associated with impacted maxillary canine 

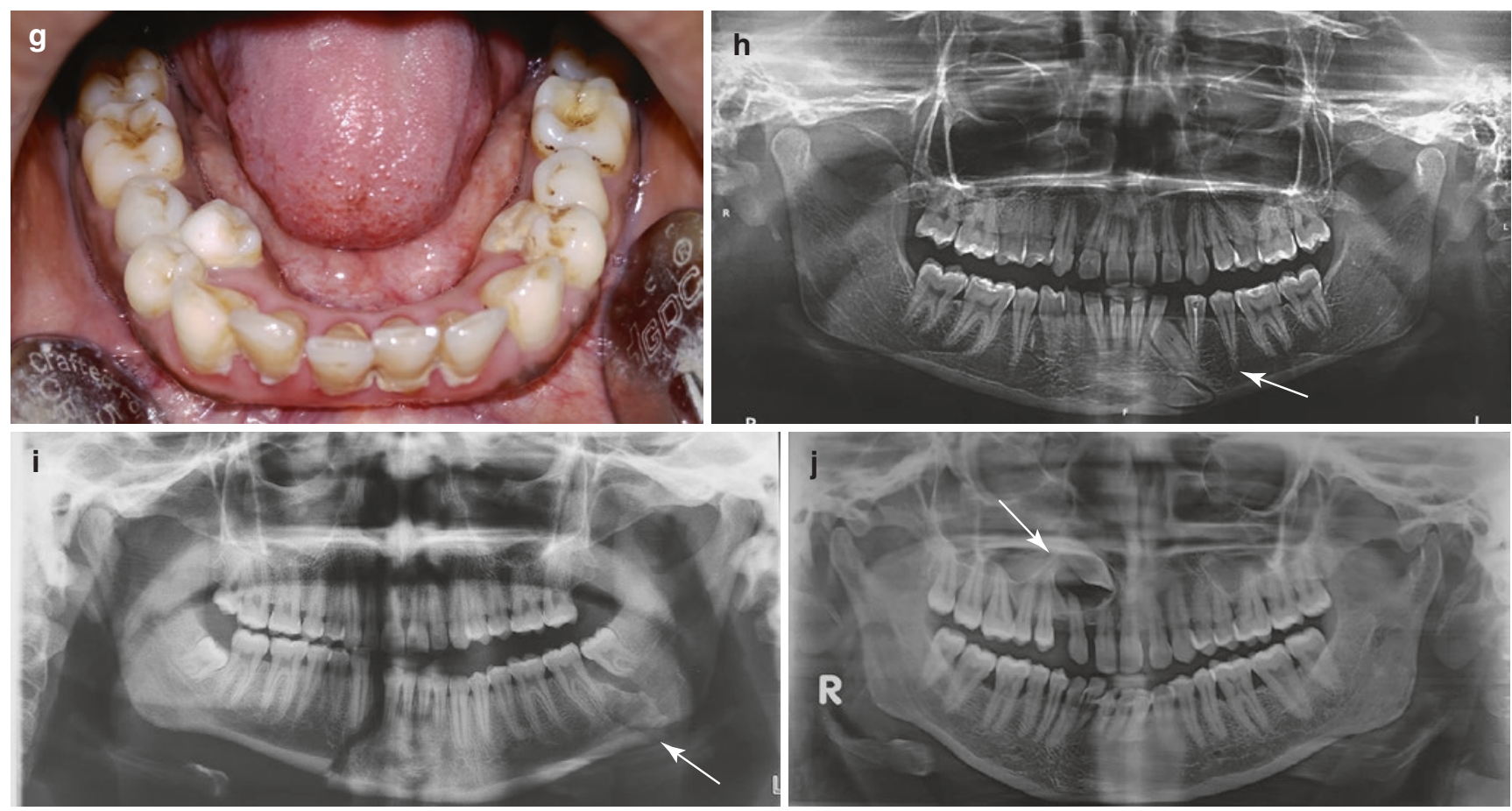

CAssociation of Oral and Maxillofacial Surgeons of India

Fig. 13.3 (continued)

\subsection{Contraindications for Exodontia}

A tooth may be indicated for extraction, but the presence of certain factors makes it contraindicated for extraction at that particular time. Any medical disorder in an uncontrolled, severe, or acute state may become a relative contraindication for extraction. However, once the underlying medical condition is controlled, the patient may be fit to undergo extraction. These relative contraindications may be classified as systemic or local contraindications.

\subsubsection{Systemic Contraindications}

Any uncontrolled systemic disease becomes a relative contraindication.

1. Neurological disorders like stroke and epilepsy.

2. Pulmonary disorders like bronchial asthma, tuberculosis, chronic obstructive pulmonary disease, and pulmonary effusion.

3. Cardiovascular disorders like hypertension, cardiomyopathy, valvular disorders, ischemic heart disease, and chronic cardiac failure.

4. Hepatic disorders like acute liver infections and liver cirrhosis.

5. Renal disorders like glomerulonephritis, uremia, and chronic renal failure.
6. Metabolic disorders like diabetes mellitus, thyrotoxicosis, Addison's disease, myxedema, and long-term steroid therapy.

7. Hematologic disorders like severe anemia, leukopenia, thrombocytopenia, pancytopenia, leukemia, agranulocytosis, patients on anticoagulant drugs, and bleeding and clotting disorders.

8. Immunocompromised patients.

\subsubsection{Local Contraindications}

1. Tooth in a malignant growth: Cases where a tooth is associated with a malignant tumor is generally mobile due to the destruction of periodontal tissues because of the underlying disease process and patients often insist for extraction. Extraction of such tooth must be considered as a relative contraindication because extraction may cause seeding of malignant cells into the capillaries subsequently leading to distant metastasis of the tumor [6].

2. Tooth associated with vascular lesions: There is a high risk of catastrophic bleeding while extracting the tooth associated with vascular lesions like hemangiomas, aneurysms, arteriovenous malformations, etc. Hence, such extractions should be carried out while treating the pathology in a controlled environment.

3. Tooth in close proximity to vital structures: The extraction should be avoided to prevent injury to vital structures. 
However, if it is unavoidable, may be performed, but meticulously.

4. Tooth in an irradiated jaw: An irradiated jaw is highly avascular; carrying out the extraction of a tooth in such condition is associated with a high risk of osteoradionecrosis. However, such a tooth can be extracted after a considerable period of time following radiation therapy [8].

5. Tooth with an acute infection: If a tooth associated with acute infective pathology is extracted, there is a risk of extension of infection into deeper tissue planes due to loss of natural barriers during surgery. Also, there are chances of ingress of microorganisms into blood stream resulting in bacteremia. This may cause pyrexia and bacterial endocarditis in susceptible patients. Hence, in such a situation, the tooth must be extracted under proper antibiotic coverage. Apart from antibiotics, local measures for the drainage or decompression of the infective pathology should be carried out if possible. This relieves the pain and discomfort of the patient [9].

\subsection{Armamentarium for Exodontia [10, 11]}

\subsubsection{Forceps}

Forceps are the basic instruments used to perform exodontia. They are based on principles of simple machines. Forceps are designed to provide adequate access to the targeted tooth without injuring the neighboring tissues. Forceps basically have three components: (Fig. 13.4).

- The handle: Handle is the area of forceps from where the operator holds the instrument in a palm grip. It has serrations to facilitate firm grip. It is longer as compared to the beaks,

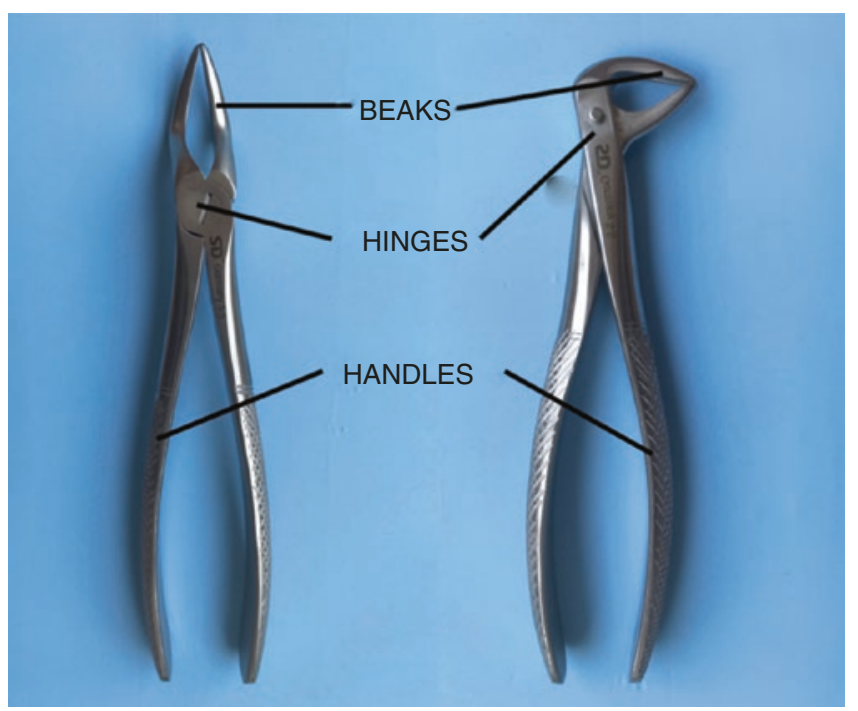

CAssociation of Oral and Maxillofacial Surgeons of India

Fig. 13.4 Components of forceps corresponding to the longer arm of the lever, providing maximum mechanical advantage.

- The Hinge: It the area where the beaks and handle unite with each other and this part corresponds to the fulcrum of the lever.

- The beaks: Beaks are shorter as compared to the handle and correspond to the short arm of the lever, providing maximum mechanical advantage. The beaks of maxillary forceps are parallel to the handle, whereas the beaks of mandibular forceps are at a right angle. This helps in the application of beaks parallel to the long axis of the tooth. The beaks are curved and designed specifically for different teeth for proper two-point contact. The outer surface of beaks are smooth and tapering, facilitating wedging between the tooth and alveolar process. However, the inner surface of beaks are serrated to provide a firm grip over the tooth.

The forceps are of two types:

1. English Pattern: These forceps have a hinge that is directed vertically to the handles of the forceps.

2. American Pattern: These forceps have a hinge that is directed in a horizontal direction with the handles of the forceps.

Tables 13.4 and 13.5 describe various maxillary and mandibular forceps with their salient features, respectively.

Maxillary forceps must be held in a 'palm up' position (Fig. 13.7a) and mandibular forceps must be held in a 'palm down' position (Fig. 13.7b). These forceps majorly apply five different motions: (Fig. 13.8).

1. Apical pressure: With the force in this direction, the tooth movement is minimal in apical direction; however, the socket expands due to insertion of beaks in the periodontal ligament space. Also, the center of rotation of tooth displaces apically, resulting in less amount of force at the apical portion of root preventing it from getting fractured. (Fig. 13.9).

2. Buccal/Labial pressure: This results in expansion of buccal cortical plate, specifically at the crest of the ridge. However, at the same time, it results in lingual apical pressure. However, excessive pressure must be avoided to prevent fracture of buccal bone and the apical portion of the root.

3. Palatal/Lingual pressure: Similar to the buccal/labial pressure, but in opposite direction aiming in the expansion of lingual cortical plate.

4. Rotational pressure: Here the tooth is rotated resulting in internal socket expansion and tearing of periodontal ligaments. This force must only be applied to the teeth with single and conical roots. Teeth with multiple or dilacerated roots are prone to fracture on the application of this force. 
Table 13.4 Maxillary forceps with their salient features

\begin{tabular}{|c|c|c|c|}
\hline Sr. No. & Forceps & Description & Use \\
\hline 1 & $\begin{array}{l}\text { Maxillary anterior forceps } \\
\text { (Fig. 13.5a) }\end{array}$ & Beaks are approximated with each other and handle is straight & $\begin{array}{l}\text { Extraction of maxillary incisors and } \\
\text { canines. }\end{array}$ \\
\hline 2 & $\begin{array}{l}\text { Maxillary premolar forceps } \\
\text { (Fig. 13.5b) }\end{array}$ & $\begin{array}{l}\text { Beaks do not approximate. Handle has concavity on one side } \\
\text { to provide better grip and access. }\end{array}$ & Extraction of maxillary premolars. \\
\hline 3 & $\begin{array}{l}\text { Maxillary molar forceps } \\
\text { (Fig. 13.5c) }\end{array}$ & $\begin{array}{l}\text { These are paired forceps having asymmetrical and broader } \\
\text { beaks. Beak is pointed on one side which engages the buccal } \\
\text { bifurcation of roots and blunt on the other side engaging } \\
\text { palatal root. Handle is similar to that of premolar forceps. }\end{array}$ & Extraction of maxillary molars. \\
\hline 4 & $\begin{array}{l}\text { Maxillary cow horn forceps } \\
\text { (Fig. 13.5d) }\end{array}$ & $\begin{array}{l}\text { These are also paired forceps having beaks that resemble the } \\
\text { horns of the cow, pointed on one side engaging buccal } \\
\text { bifurcation and notched on the other engaging palatal root. }\end{array}$ & $\begin{array}{l}\text { Extraction of maxillary molars with } \\
\text { extensive loss of coronal structure. }\end{array}$ \\
\hline 5 & $\begin{array}{l}\text { Maxillary third molar forceps } \\
\text { (Fig. 13.5e) }\end{array}$ & $\begin{array}{l}\text { Beaks are curved and angulated to engage the crown of third } \\
\text { molars. Handle is long for accessing the posterior region. }\end{array}$ & Extraction of maxillary third molars \\
\hline 6 & $\begin{array}{l}\text { Maxillary bayonet forceps } \\
\text { (Fig. 13.5f) }\end{array}$ & $\begin{array}{l}\text { Beaks of the forceps are narrow, symmetrical, and } \\
\text { approximating. Handle is angulated to provide access to } \\
\text { posterior areas as well. }\end{array}$ & Extraction of maxillary roots. \\
\hline
\end{tabular}
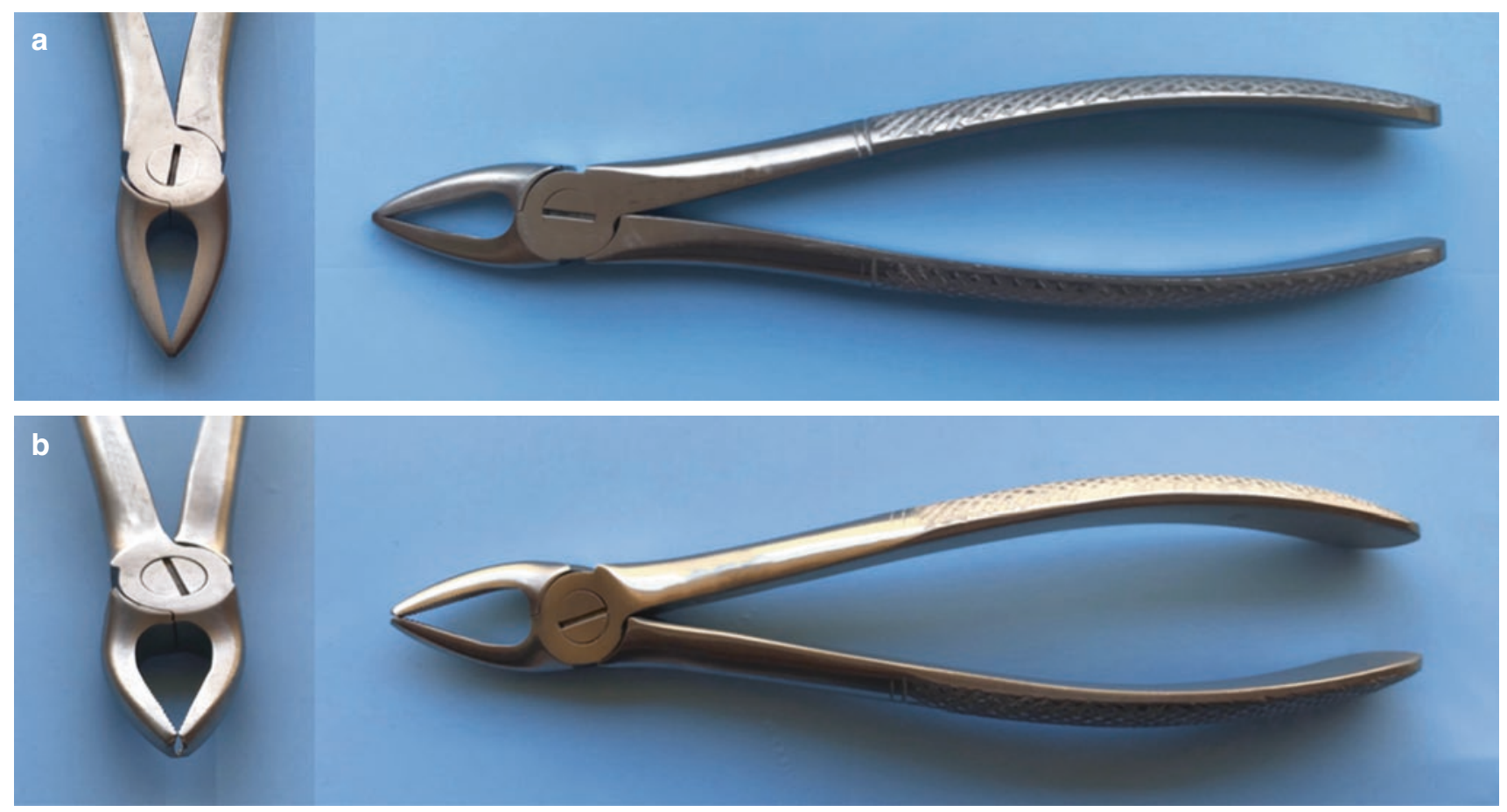

Fig. 13.5 (a) Maxillary anterior forceps, (b) Maxillary premolar forceps, (c) Maxillary molar forceps, (d) Maxillary cow horn forceps, (e) Maxillary third molar forceps, (f) Maxillary bayonet forceps 

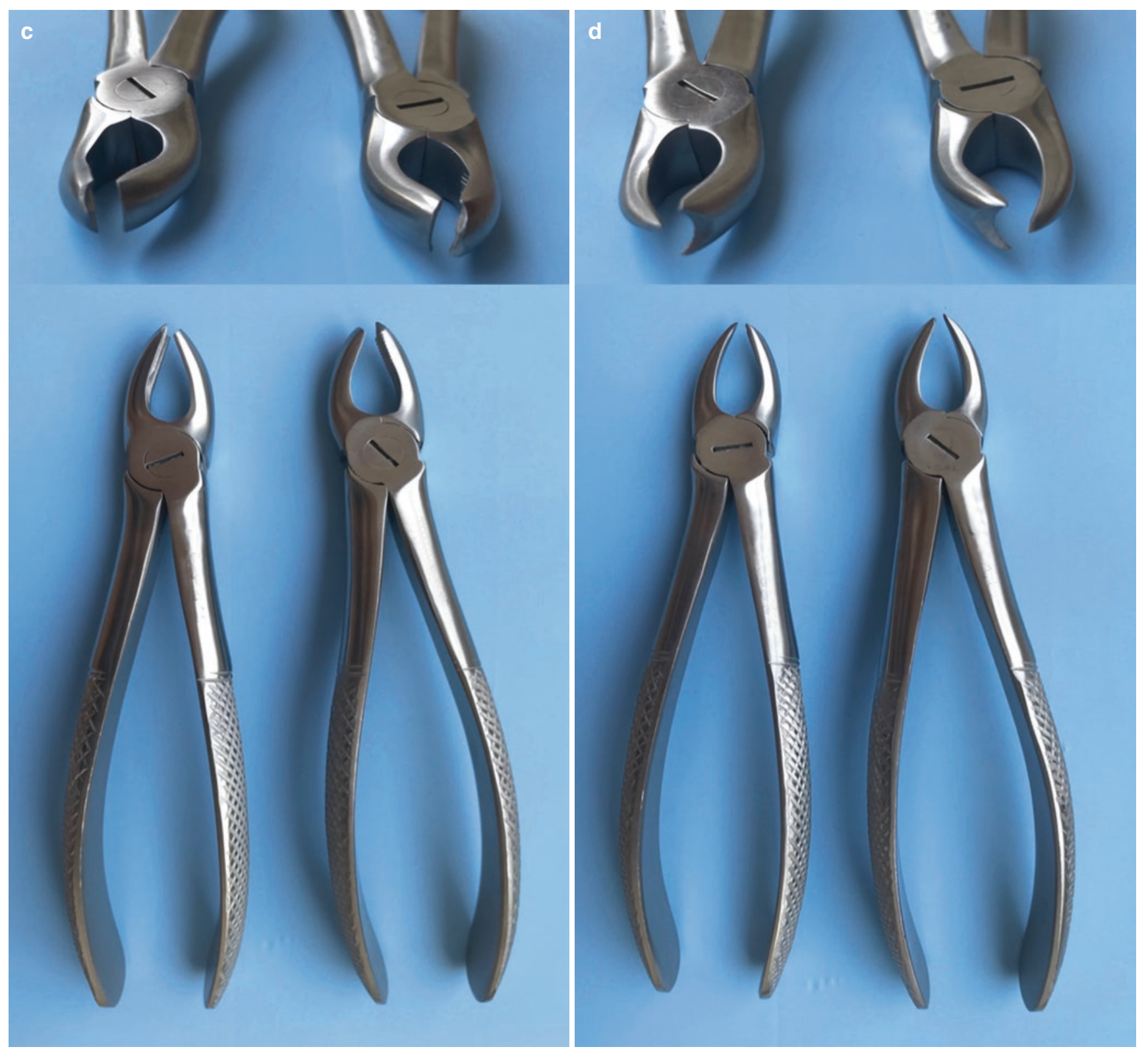

Fig.13.5 (continued) 

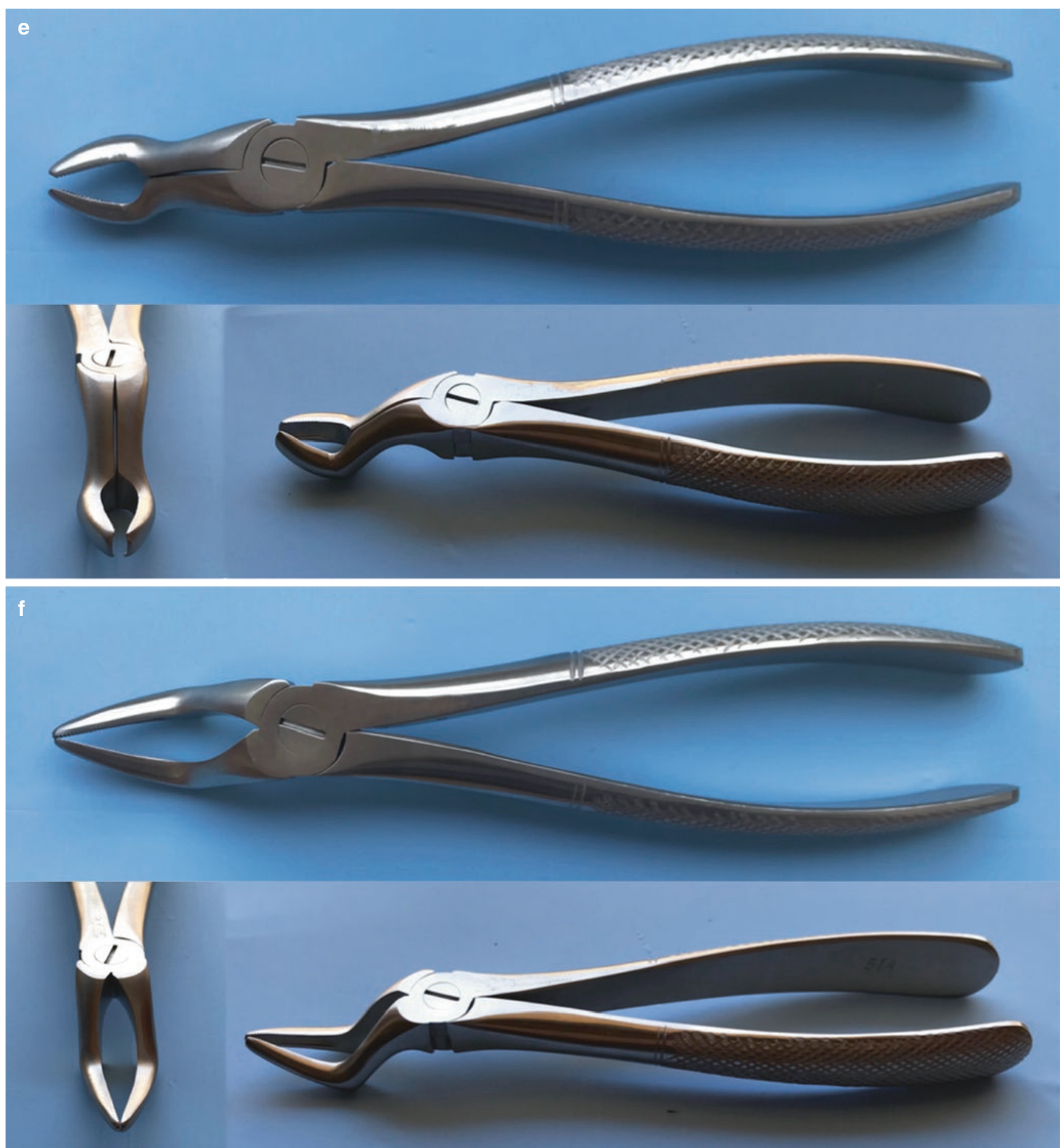

CAssociation of Oral and Maxillofacial Surgeons of India

Fig. 13.5 (continued) 
Table 13.5 Mandibular forceps with their salient features

\begin{tabular}{|c|c|c|c|}
\hline Sr. No. & Forceps & Description & Use \\
\hline 1 & $\begin{array}{l}\text { Mandibular anterior forceps } \\
\text { (Fig. 13.6a) }\end{array}$ & $\begin{array}{l}\text { Beaks are perpendicular to handle, approximating each other, } \\
\text { and handle is straight with no curvature }\end{array}$ & $\begin{array}{l}\text { Extraction of mandibular incisors and } \\
\text { canines }\end{array}$ \\
\hline 2 & $\begin{array}{l}\text { Mandibular premolar forceps } \\
\text { (Fig. 13.6b) }\end{array}$ & $\begin{array}{l}\text { Beaks do not approximate. Handle is similar to the anterior } \\
\text { forceps }\end{array}$ & Extraction of mandibular premolars \\
\hline 3 & $\begin{array}{l}\text { Mandibular molar forceps } \\
\text { (Fig. 13.6c) }\end{array}$ & $\begin{array}{l}\text { Beaks are broader with triangular projections to engage the } \\
\text { buccal and lingual furcations }\end{array}$ & Extraction of 1 \\
\hline 4 & $\begin{array}{l}\text { Mandibular cow horn forceps } \\
\text { (Fig. 13.6d) }\end{array}$ & $\begin{array}{l}\text { Beaks are pointed and conical resembling the horns of cow. } \\
\text { Beaks engage the furcations }\end{array}$ & $\begin{array}{l}\text { Extraction of mandibular molars with } \\
\text { extensive loss of coronal structure }\end{array}$ \\
\hline 5 & $\begin{array}{l}\text { Mandibular third molars } \\
\text { (Fig. 13.6e) }\end{array}$ & $\begin{array}{l}\text { These are paired forceps having an angulated beak to reach up } \\
\text { to the mandibular third molars. Both beaks have triangular } \\
\text { projections to engage the buccal and lingual furcation }\end{array}$ & Extraction of mandibular third molars \\
\hline 6 & $\begin{array}{l}\text { American pattern mandibular } \\
\text { molar forceps (Fig. 13.6f) }\end{array}$ & $\begin{array}{l}\text { Beaks are similar to that of mandibular molar forceps except } \\
\text { that they are facing forward toward each other at right angles }\end{array}$ & n of mandibular molars \\
\hline
\end{tabular}
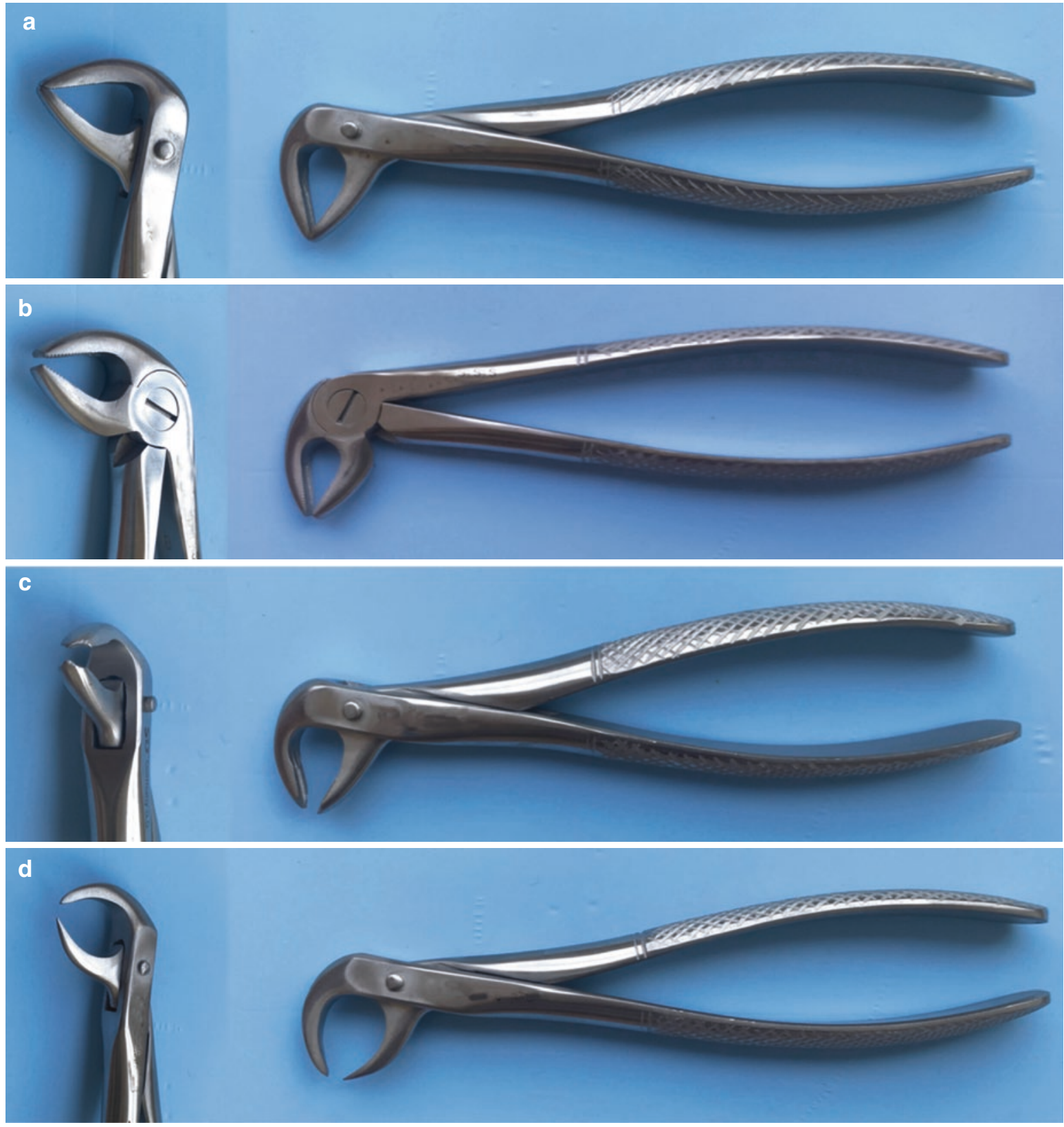

Fig. 13.6 (a) Mandibular anterior forceps, (b) Mandibular premolar forceps, (c) Mandibular molar forceps, (d) Mandibular cow horn forceps, (e) Mandibular third molar forceps, (f) Mandibular molar forceps (American pattern) 


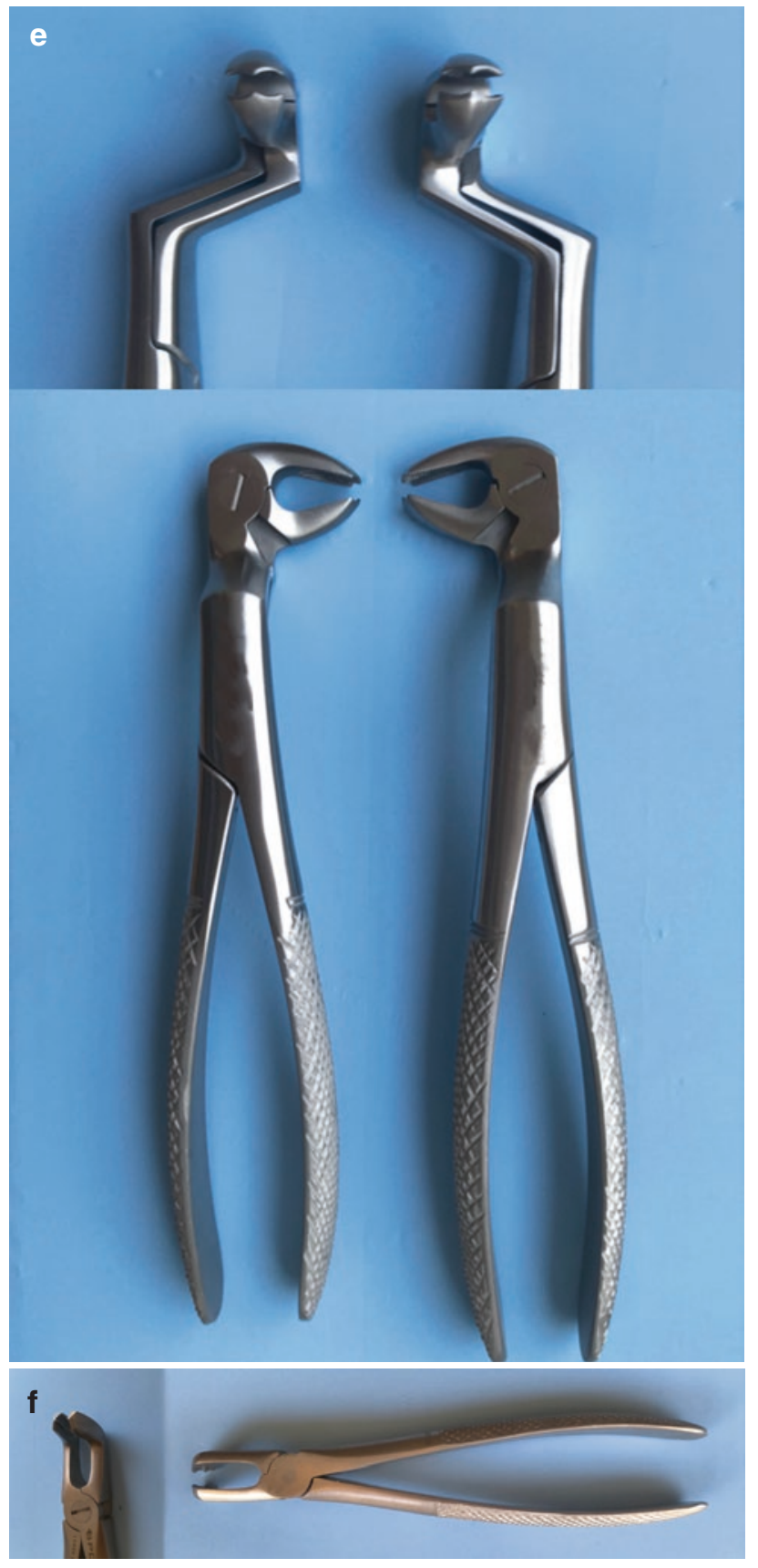

CAssociation of Oral and Maxillofacial Surgeons of India

Fig. 13.6 (continued)

5. Tractional forces: This delivers the tooth out of the socket. This force should be gentle and the tooth should not be pulled out of the socket. However, if excessive force is required, other maneuvers must be carried out to improve luxation.
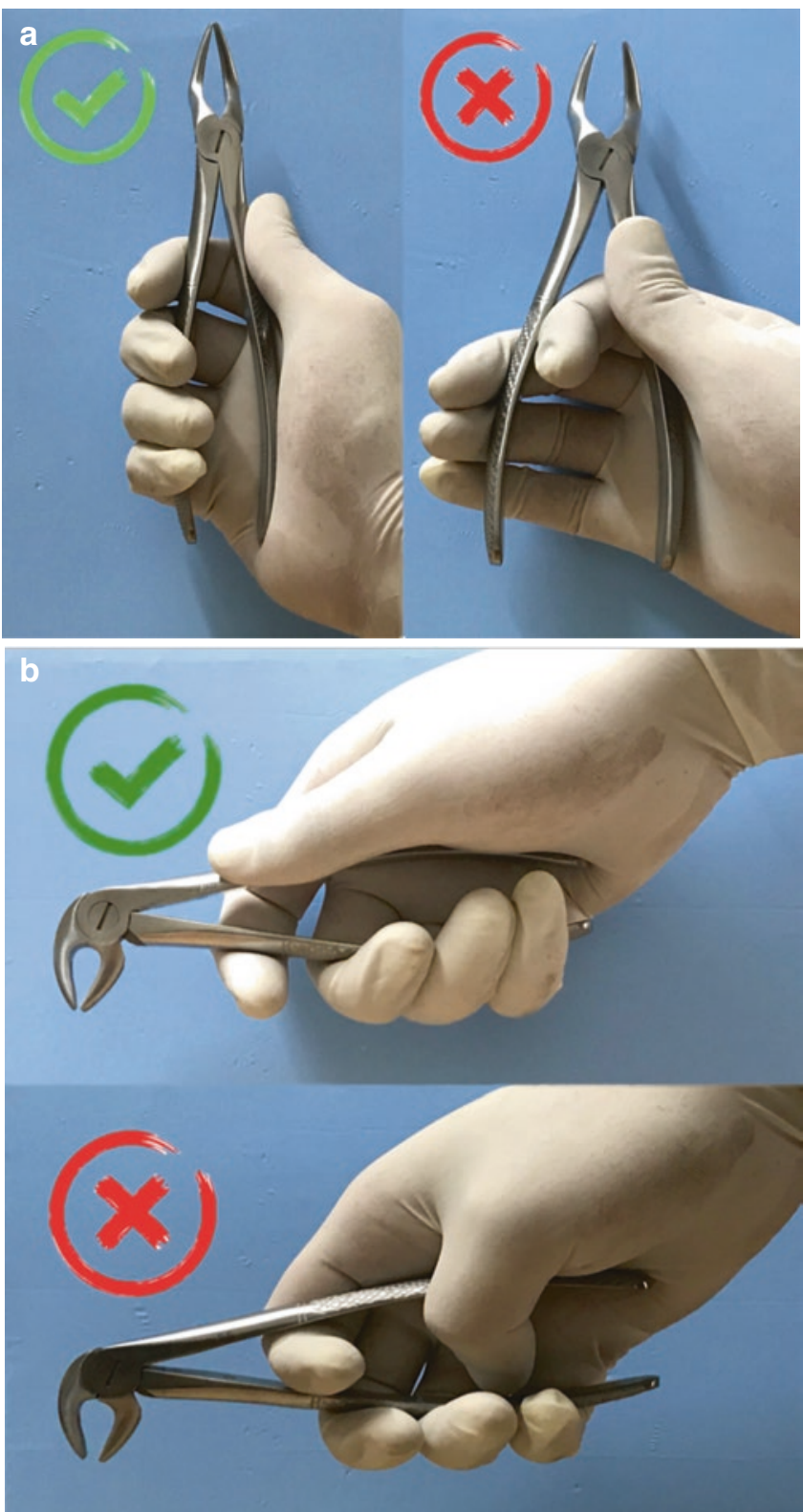

CAssociation of Oral and Maxillofacial Surgeons of India

Fig. 13.7 (a) Correct way of holding maxillary forceps, (b) Correct way of holding mandibular forceps

\subsubsection{Elevators}

Elevators are the instruments used for luxating (loosening) the teeth before application of forceps making extraction easier, subsequently avoiding complications like fracture of crowns, roots, and bone. They are also used to remove fractured or surgically sectioned roots. Elevators are singlebladed instruments designed for specific purposes deliver- 


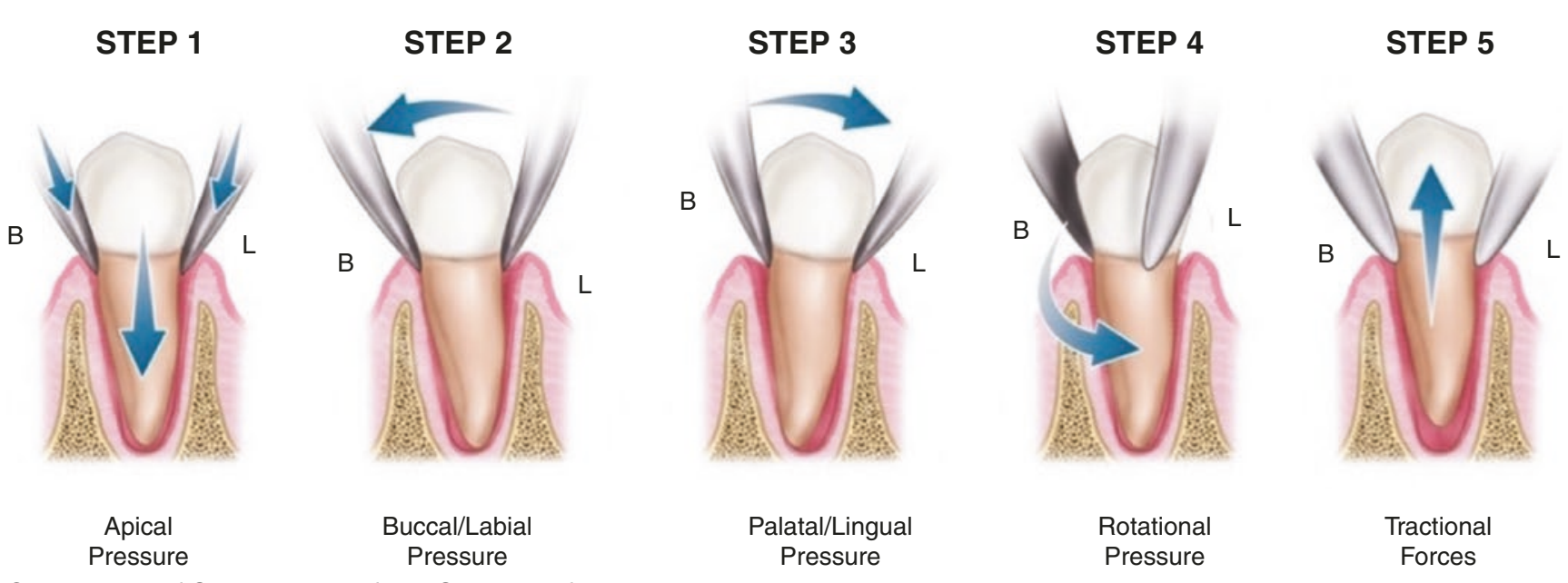

CAssociation of Oral and Maxillofacial Surgeons of India

Fig. 13.8 Sequential motions performed using forceps

Fig. 13.9 Center of rotation of tooth gets displaced apically when the forceps is inserted beyond cementoenamel junction
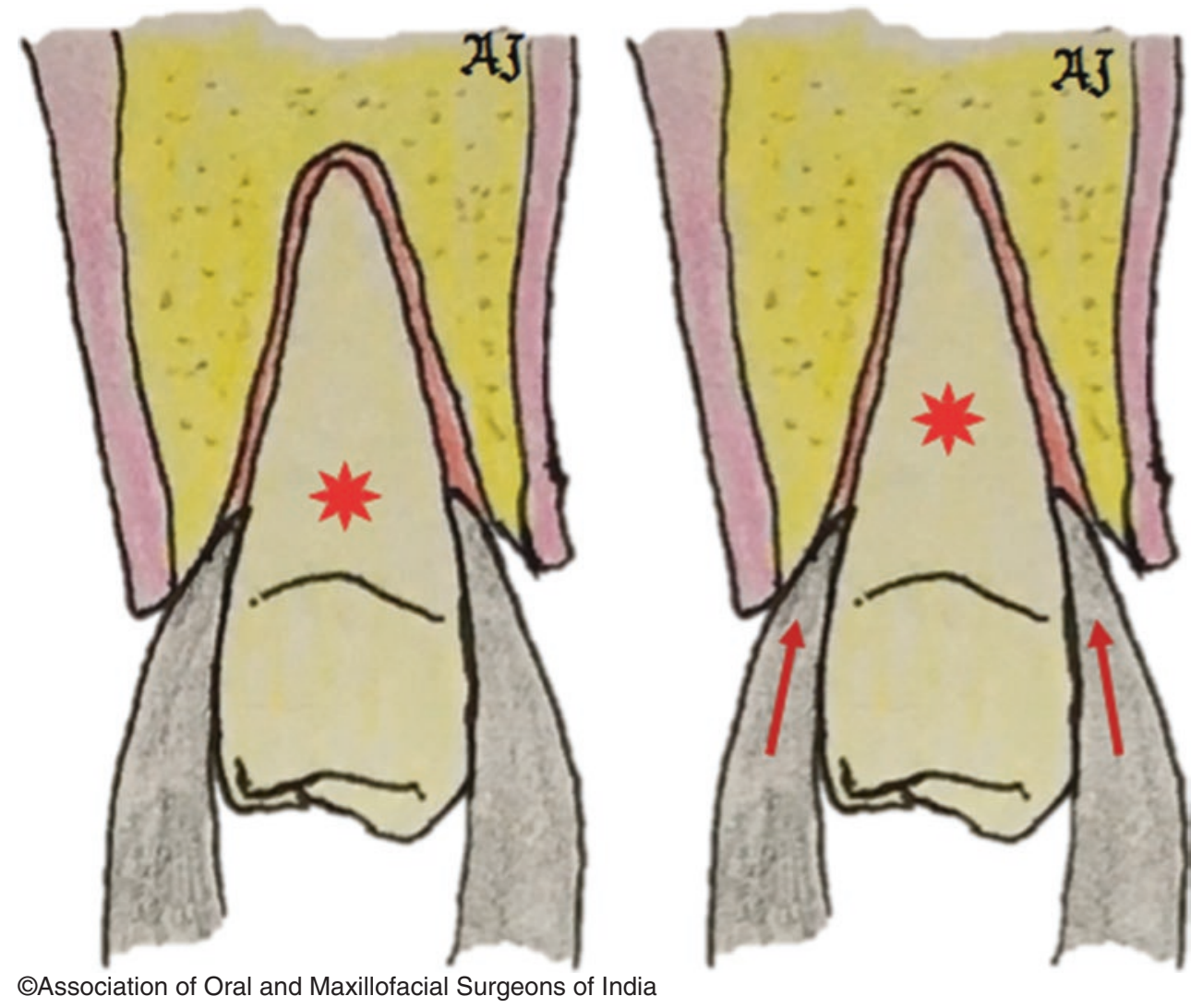

ing maximum mechanical advantage with minimum efforts. Elevators have three components (Fig. 13.10):

- Handle: It is of generous size for proper grip and delivering adequate but controlled force. Handle can be a continuation of the shank or at a right angle to the shank.

- Shank: It connects the handle with the working end or blade of the elevator. It is strong enough to transmit the force from the handle to the blade.
- Blade: It is the working end of the instrument and transmits the force to the tooth, bone, or both to achieve the desired action.

Table 13.6 highlights various types of elevators used for exodontia and Fig. 13.12 shows the proper way to hold an elevator. 


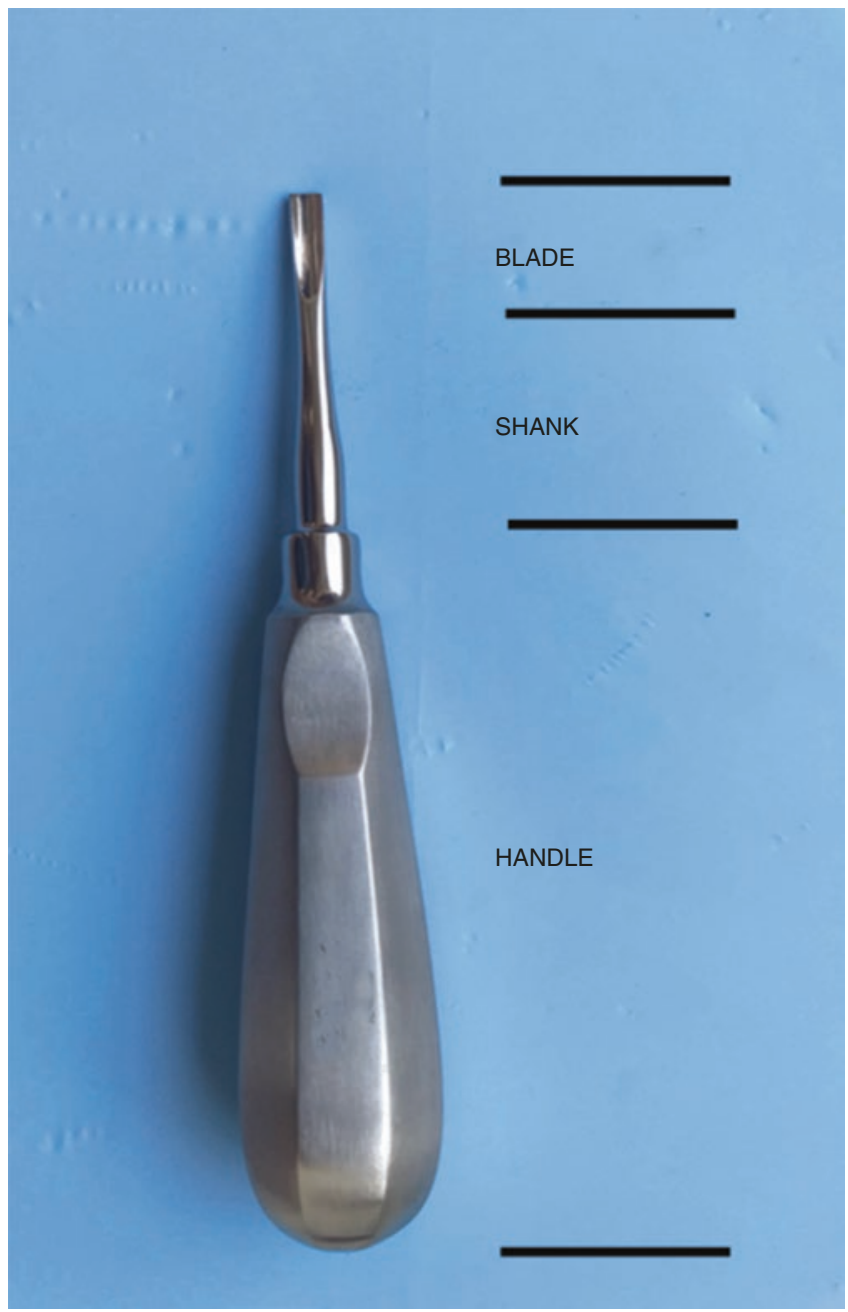

(CAssociation of Oral and Maxillofacial Surgeons of India

Fig. 13.10 Components of elevator

Elevators works on principles of
1. Wedge
2. Lever
3. Wheel and Axle
4. Combination of the above

Table 13.6 Elevators with their salient features

\begin{tabular}{ll|l|l}
$\begin{array}{l}\text { Sr. } \\
\text { No }\end{array}$ & Elevator & Description & Use \\
\hline 1 & $\begin{array}{l}\text { Straight elevator } \\
\text { (Fig. 13.11a) }\end{array}$ & $\begin{array}{l}\text { The blade, shank, and } \\
\text { handle are in one line. } \\
\text { Blade is pointed with } \\
\text { one surface serrated and } \\
\text { other convex. }\end{array}$ & $\begin{array}{l}\text { Luxation of } \\
\text { maxillary and } \\
\text { mandibular teeth }\end{array}$ \\
\hline
\end{tabular}

2 Coupland elevator The blade, shank, and handle are in one line.

(Fig. 13.11b) Blade is sharp and straight cut having one surface concave and other convex.

3 Apexo elevator These are paired (Fig. 13.11c) elevators with blade at an angulation of $45^{\circ}$ to shank. This facilitates its reach up to roots' apical region.

4 Cross Bar elevator These are paired

Acts as a wedge to create purchase. Splitting of tooth

(Fig. 13.11d)

evators with blade at a right angle to shank and shank at a right angle to handle. The blade is triangular with slight curve and pointed tip.

5 Cryer elevator There are paired elevators similar to cross bar elevator. The only difference is that the handle is parallel to the shank.

6 Warwick James elevator

(Fig. 13.11f) The blade is short with
rounded end and the handle is flattened.

There are three elevators, two angled (mesial and distal) and one straight.

7 Root tip elevator or root fragment ejector

It can be a single or

Extraction of roots Elevation of upper third molars

Extraction of root pieces

Extraction of mandibular roots

Extraction of retained roots, deciduous teeth, maxillary third molars, and teeth with less resistance

Removal of apical double ended instrument root tips/fragments similar to Apexo of roots

(Fig. 13.11g) elevators. The only difference is that they are smaller with more pointed blades 

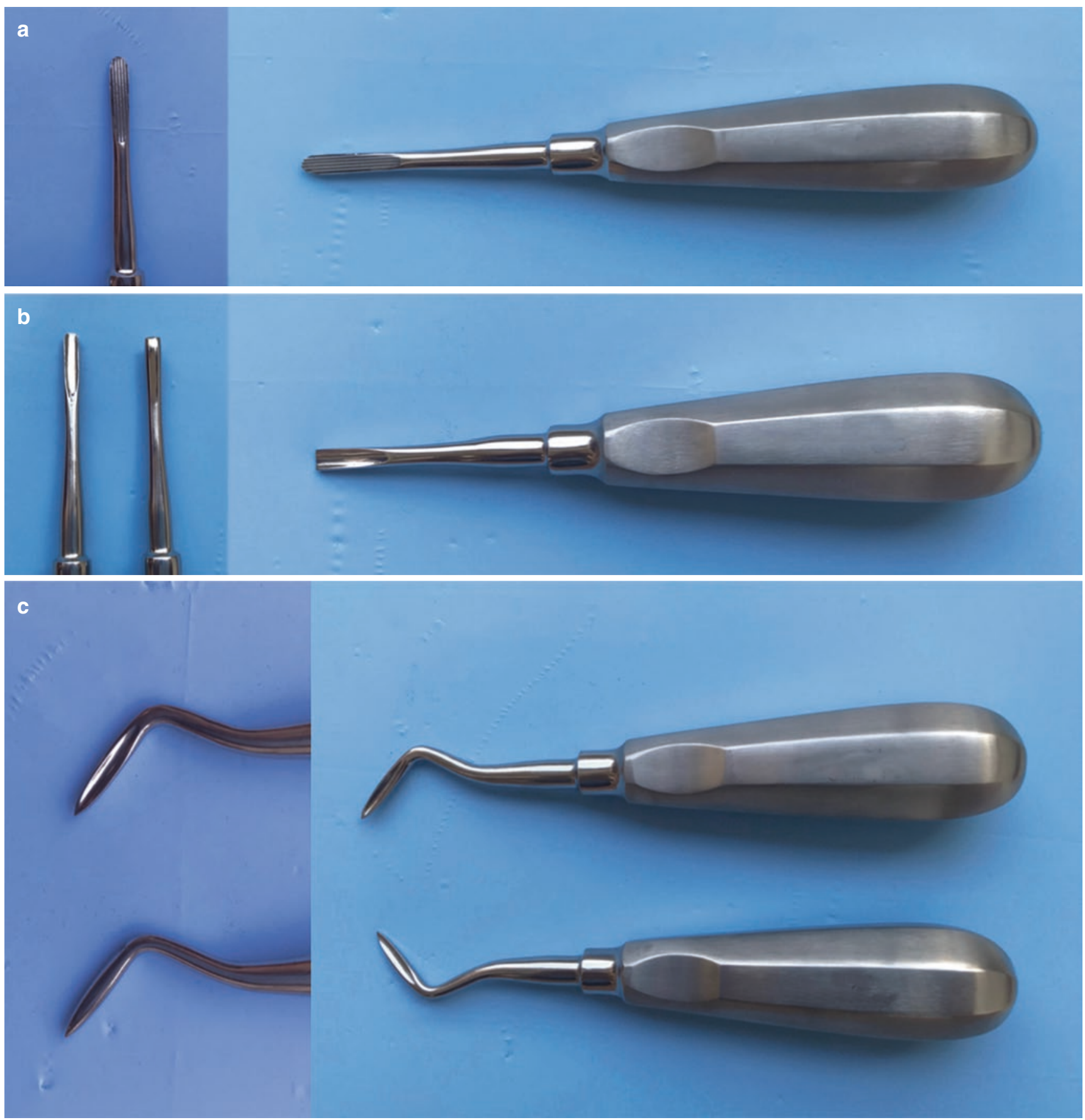

Fig. 13.11 (a) Straight elevator, (b) Coupland elevator, (c) Apexo elevator, (d) Cross bar elevator, (e) Cryer elevator, (f) Warwick James elevator, (g) Root tip elevator 

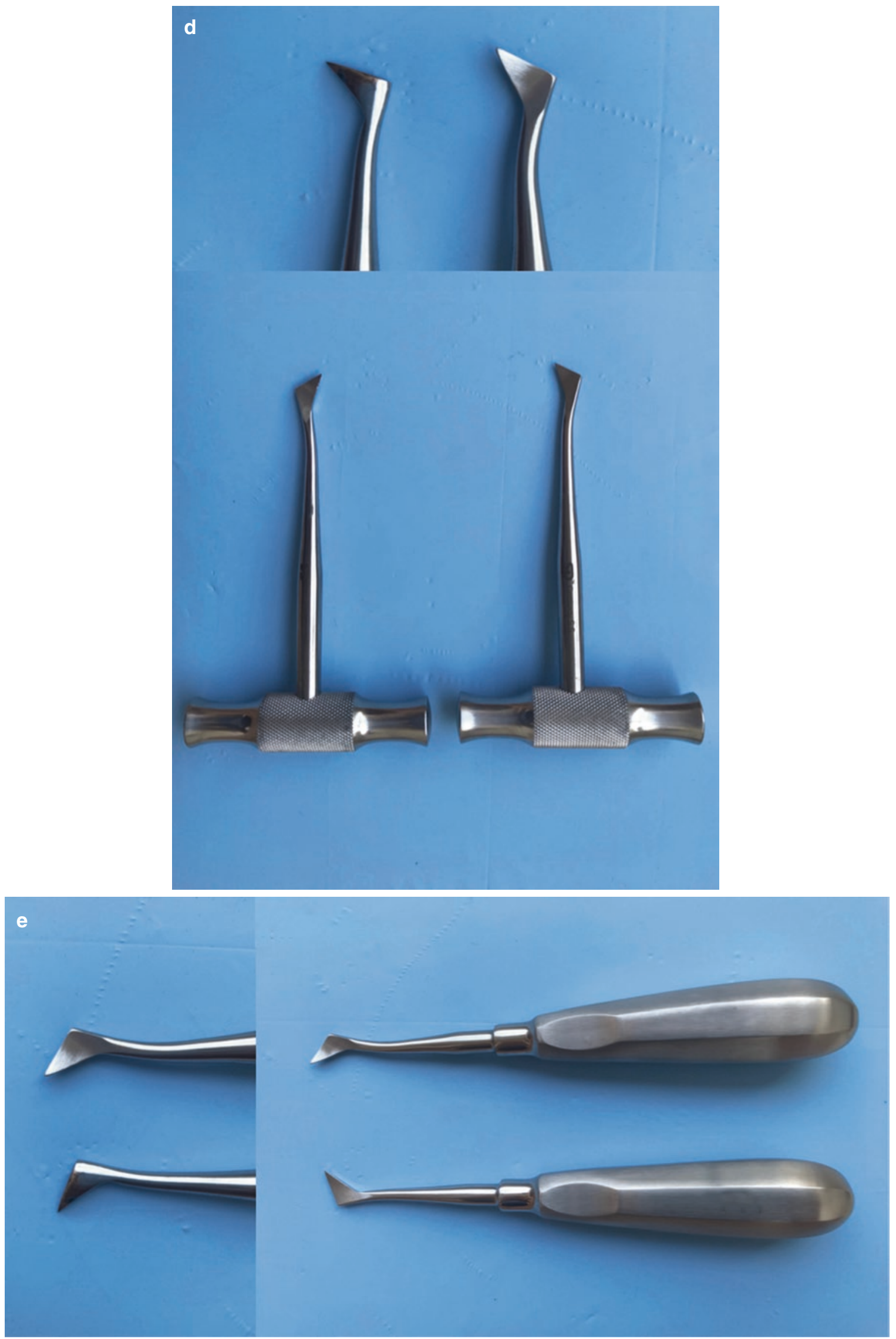

Fig. 13.11 (continued) 

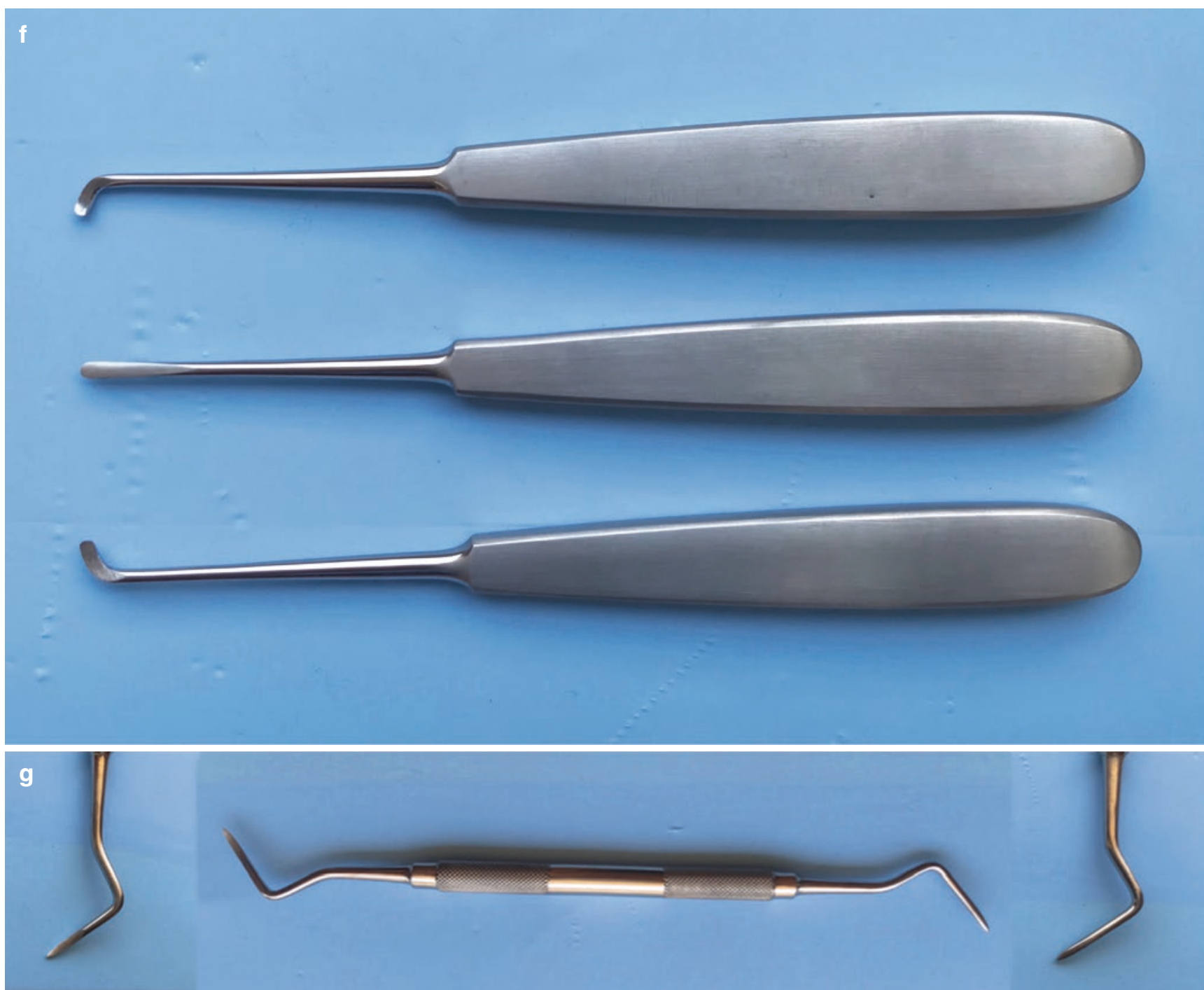

(C)Association of Oral and Maxillofacial Surgeons of India

Fig. 13.11 (continued) 

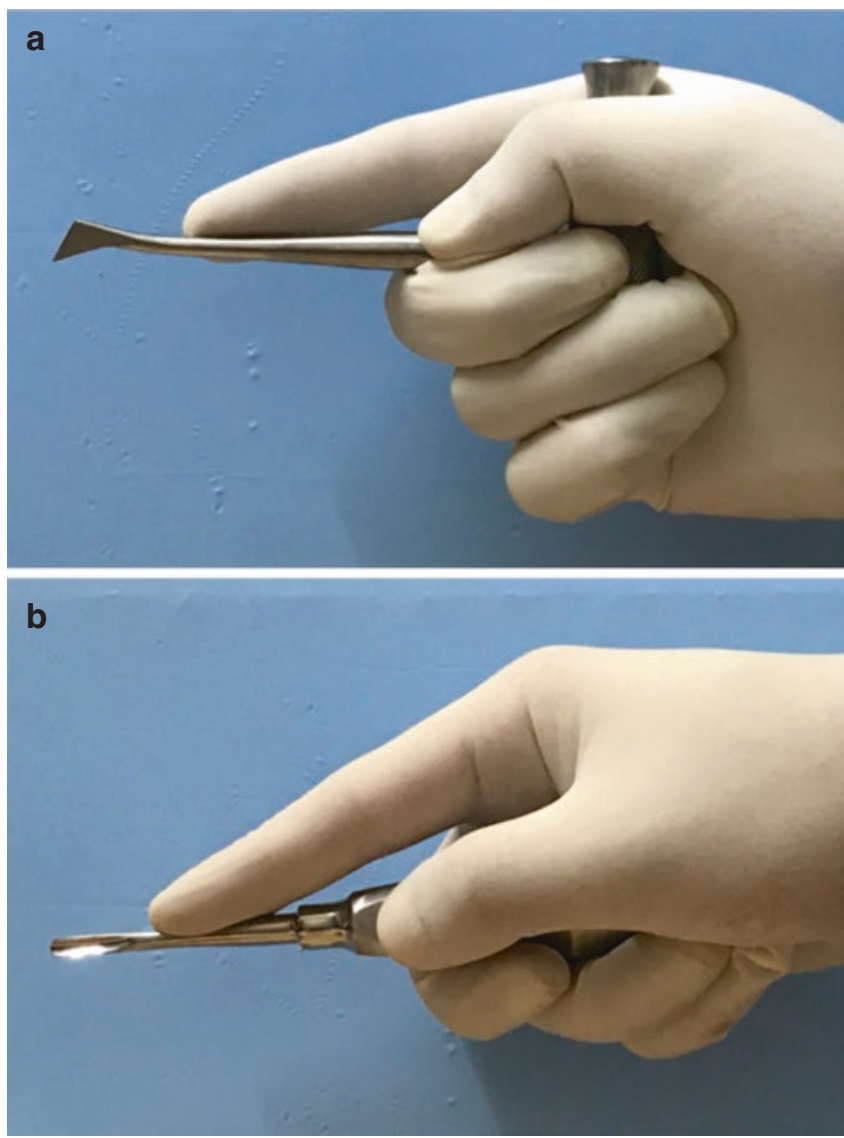

CAssociation of Oral and Maxillofacial Surgeons of India

Fig. 13.12 (a, b) Correct way of holding an elevator

1. Wedge Principle: Introduction of the blade of an elevator between the bone and tooth parallel to the long axis of the tooth is wedging. A wedge is basically a movable inclined plane which overcomes a larger resistance at right angle to the applied effort. The resistance has its effect on the slant side when the effort is applied at the base of the plane (Fig. 13.13a and b).

2. Lever Principle: The elevator is the lever of first class. To gain mechanical advantage in first-class lever, the effort arm must be longer (3/4th of the total length) than the resistance arm divided by the fulcrum which lies on the bone (Fig. 13.14a and b).

3. Wheel and Axle Principle: In this principle, the effort is applied to the circumference of a wheel, which turns the axle generating the force to raise a weight (Fig. 13.15).

\subsection{Sequential Procedure of Exodontia} $[6,10]$

The procedure of exodontia is a blend of surgical principles and elementary physics mechanics. When this combination is applied efficiently, a tooth can be removed with no great difficulty and finesse without requiring a large amount of force. For an uneventful extraction to be carried out, a proper sequential procedure must be followed.

\subsubsection{Presurgical Assessment}

- Presurgical Medical Risk Assessment:

The approach of a dental surgeon must not be localized to a diseased tooth. It should always be kept in mind that we are not treating a tooth but we are treating an individual with a diseased tooth. It is critical that the surgeon must examine the patients' medical status. Patients may suffer from a variety of medical ailments requiring modification in treatment planning. Medical management must be carried out first for safe extraction procedure for the patient.

- Emotional Condition of the patient:

Due to various myths like weakening of eyesight and impact on mental health following extraction as well as severe intolerable pain during the procedure, the patients are generally apprehensive to undergo extraction. Such patients are liable to go into syncope or aggravation of their medical condition. A proper counseling is required in such cases before proceeding for exodontia. However, in extremely anxious patients, where counseling is not enough, premedication like Diazepam/Alprazolam (Anxiolytics) for reduction of anxiety may be considered.

- Extraoral Examination:

The patient must be examined for the presence of any extraoral swelling, cellulitis, abscess, or lymphadenopathy. Presence of any swelling is suggestive of extension of infection into surrounding soft tissue space which may require another surgical procedure. Presence of trismus must also be examined as it affects the access to the tooth to be extracted.

- Intraoral Examination:

It includes an examination of the size of the tongue, bulky buccal fat pad, and hyperactive gag reflex as these fac- 
Fig. 13.13 (a) Wedge principle where a wedge is used to expand, split, and displace portions of the substance that receives it, (b) The blade of the elevator is used as a wedge to displace the tooth root out of the socket
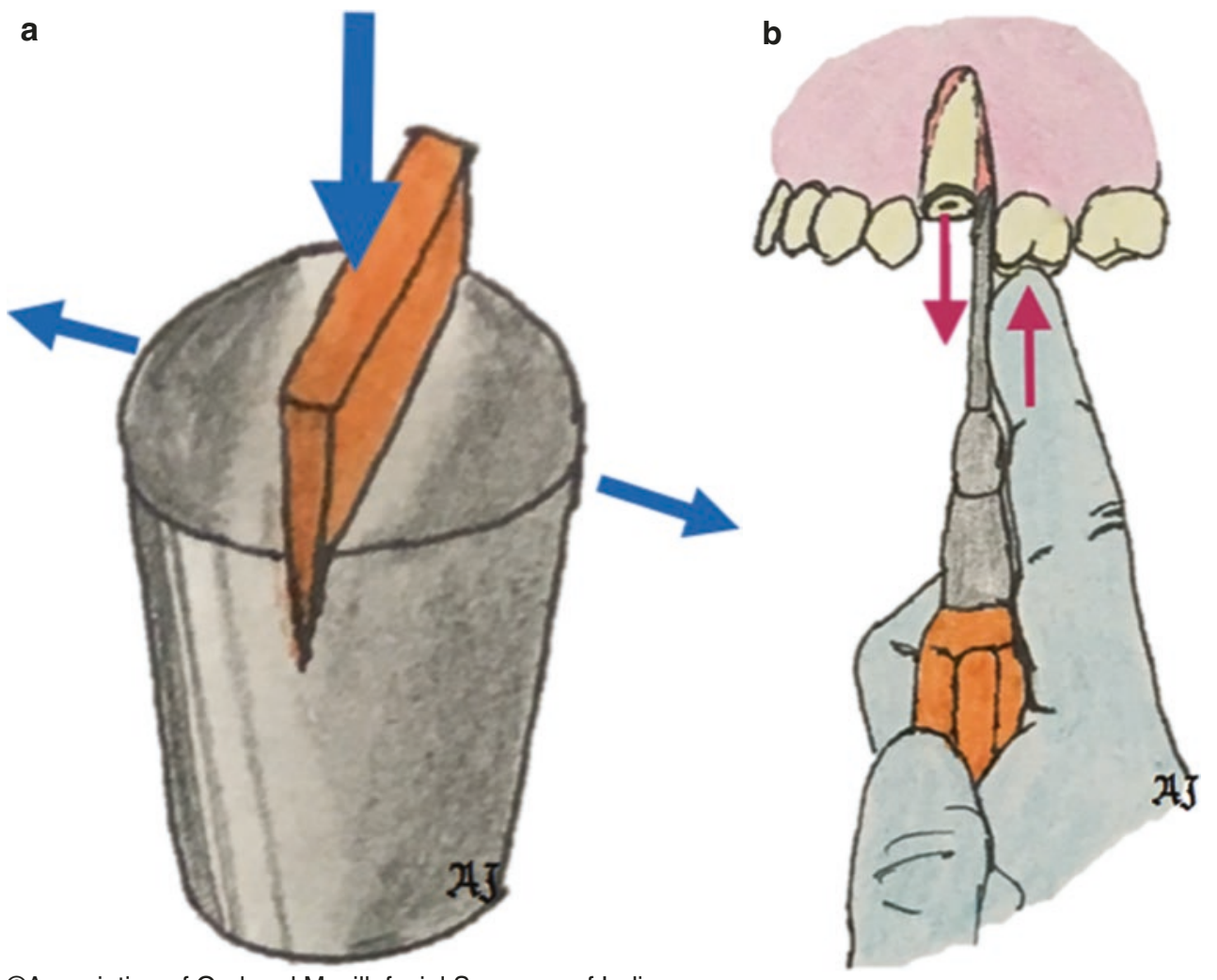

CAssociation of Oral and Maxillofacial Surgeons of India
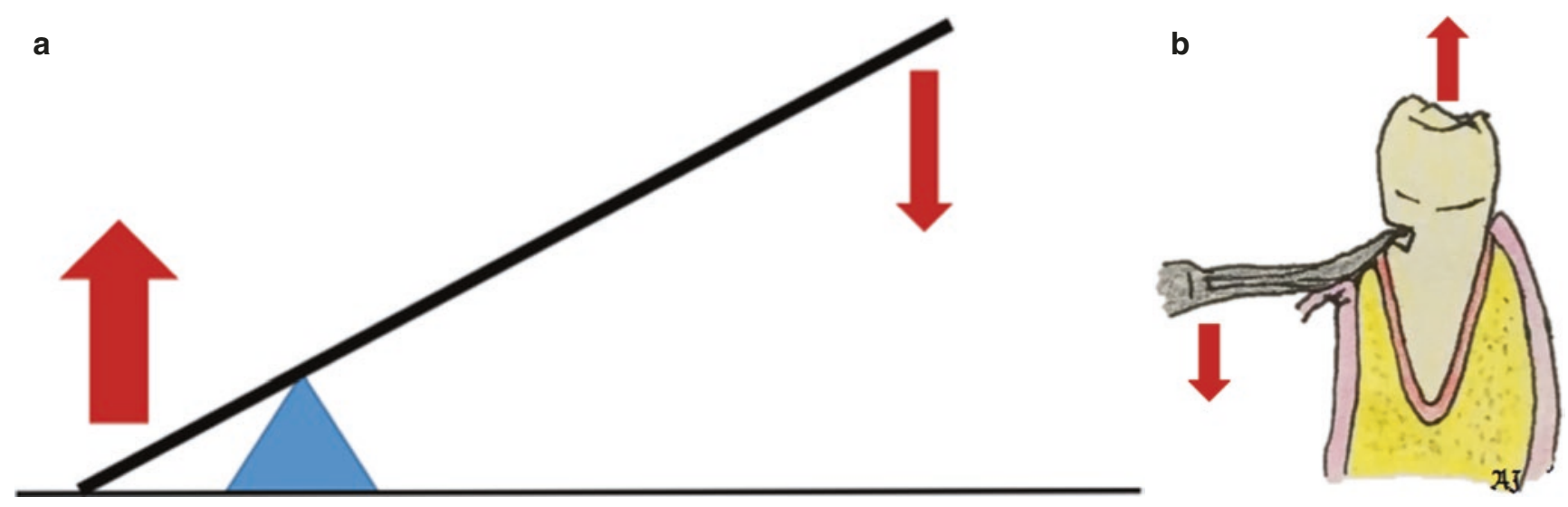

CAssociation of Oral and Maxillofacial Surgeons of India

Fig. 13.14 (a) The small force and large movement transformed to small movement and large force by the first-class lever, (b) The tooth is elevated out of the socket where the bone acts as a fulcrum 
Fig. 13.15 The elevator acting on the principle of Wheel and Axle aids in retrieval of root from the socket
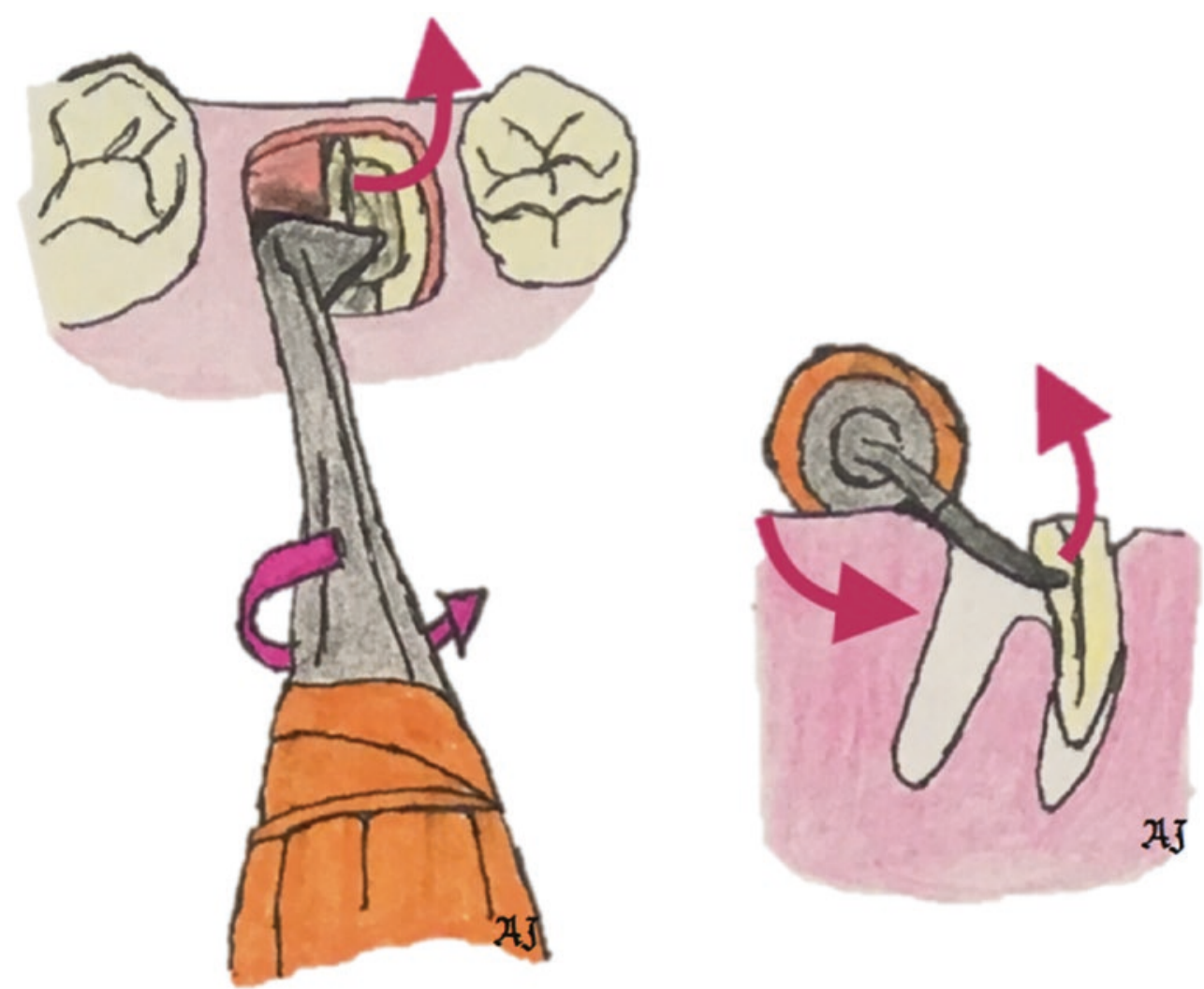

@Association of Oral and Maxillofacial Surgeons of India tors may hamper the access to the surgical site. Acute signs of infection like inflammation, edema, and pus discharge must also be assessed and the procedure must be performed under local antiseptic care and antibiotic coverage.

- Examination of the tooth in question.

This step includes a thorough examination of

- Crown size

- Form

- Shape

- Presence of caries

- Mobility

- Previous endodontic therapy

- Tooth Angulation

- Malposition

These factors play a significant role in the extraction procedure. The status of the adjacent tooth should also be examined as in its absence the interdental bone cannot be used as a fulcrum. Moreover, if it is carious, there are chances of fracture of the adjacent tooth while application of elevator in the interdental space.

- Radiographic Examination.

It is advisable to take a proper radiograph for any tooth which is to be extracted. Generally, an intraoral periapical radiograph provides accurate and sufficient details of the tooth, its root/s, and the surrounding tissue.

Examination of the following factors must be done:

- Configuration of roots

- Size of roots

- Shape of roots

- Number of roots

- Root form

- Presence of dilacerations

- Resorption

- Hypercementosis

A proper radiograph also gives an idea regarding the proximity of the root to the vital structures such as inferior alveolar neurovascular bundle and maxillary sinus. Moreover, the condition of surrounding bone can also be identified for the presence of sclerotic bone or periapical pathologies like cyst, abscess, or granuloma.

\subsubsection{Treatment Planning}

As the proverb says 'Failing to plan is planning to fail', it is of paramount importance to device a proper treatment plan before carrying out an extraction procedure. The degree 
of difficulty must be anticipated during the pre-extraction period. On assessment, if it is believed that the degree of extraction is high or the initial attempts of extraction confirm it, a deliberate surgical approach must be planned. A large amount of force during simple exodontia must be avoided as it may injure local soft tissue and damage surrounding bone and teeth. There are also chances of crown fracture which makes the procedure more difficult. Also, the application of excessive force aggravates the intraoperative and postoperative discomfort of the patient.

\subsubsection{Administration of Local Anesthesia}

Extraction of the tooth can be effectively carried out under local anesthesia. Hence, administration of local anesthesia must be carried out with proper technique and appropriate agent. For different teeth, different nerve blocks are to be given (Tables 13.2 and 13.3). Once the local anesthesia, nerve block and/or local infiltration is administered, surgeon must wait for it to act and confirm the same by subjective and objective tests.

\subsubsection{Surgeon and Patient Preparation}

The principle of universal precaution states that all the patients must be viewed as having blood-borne diseases that can be transmitted to the surgical team and other patients. Hence, to avoid transmission of diseases, a surgeon and the assistant must wear surgical gloves, surgical mask, eye-wear with shields, surgical cap, and a long-sleeved surgical gown. Before the patient is subjected to the extraction procedure, a sterile drape should be put over the patient's chest to decrease the risk of contamination. It is advisable to reduce the bacterial contamination in the patient's mouth by making him/ her rinse the mouth vigorously using an antiseptic rinse like chlorhexidine prior to the procedure. Some surgeons prefer to keep a partially unfolded $4 \times 4$ inches' gauze loosely into the back of the mouth to prevent the tooth or its fragment from potential aspiration or swallowing. However, it should not be kept posterior enough to trigger gag reflex.

\subsubsection{Position of Operator, Patient, and Chair}

The positions of the operator, the patient, and the chair are very important for comfortable and successful extraction. The best position is one that is comfortable for both the patient and surgeon and which allows the surgeon to have maximum control during the procedure.
Table 13.7 Chair and patient positions for extraction

\begin{tabular}{|c|c|c|}
\hline & Maxillary extraction & Mandibular extraction \\
\hline $\begin{array}{l}\text { Operator } \\
\text { standing }\end{array}$ & $\begin{array}{l}\text { - Chair tipped backward } \\
\text { - Maxillary Occlusal plane } \\
\text { at } 45^{\circ} \text { to the floor } \\
\text { Patient's mouth should } \\
\text { be at the level between } \\
\text { the operator's shoulder } \\
\text { and elbow }\end{array}$ & $\begin{array}{l}\text { - Upright position } \\
\text { - Mandibular occlusal } \\
\text { plane parallel to floor } \\
\text { - Patient's mouth should } \\
\text { be at the level slightly } \\
\text { below the operator's } \\
\text { elbow }\end{array}$ \\
\hline $\begin{array}{l}\text { Operato } \\
\text { sitting }\end{array}$ & $\begin{array}{l}\text { - Supine position }\left(10^{\circ} \text { to }\right. \\
\text { ground) } \\
\text { - Patient's mouth should } \\
\text { be at the level of } \\
\text { operator's elbow }\end{array}$ & $\begin{array}{l}\text { - Supine position }\left(20^{\circ}-30^{\circ}\right. \\
\text { to ground) } \\
\text { - Patient's mouth should be } \\
\text { at the level slightly above } \\
\text { the operator's elbow }\end{array}$ \\
\hline
\end{tabular}

Table 13.8 Operator's standing position for extraction

\begin{tabular}{|l|l|l|} 
Teeth & $\begin{array}{l}\text { Position for right } \\
\text { handed operator }\end{array}$ & $\begin{array}{l}\text { Position for left } \\
\text { handed operator }\end{array}$ \\
\hline $\begin{array}{l}\text { All maxillary teeth and } \\
\text { mandibular anterior teeth }\end{array}$ & $\begin{array}{l}7 \mathrm{O}^{\prime} \text { clock }-8 \mathrm{O}^{\prime} \\
\text { clock }\end{array}$ & $\begin{array}{l}4 \mathrm{O}^{\prime} \text { clock }-5 \mathrm{O}^{\prime} \\
\text { clock }\end{array}$ \\
\hline $\begin{array}{l}\text { Mandibular left posterior } \\
\text { teeth }\end{array}$ & $\begin{array}{l}7 \mathrm{O}^{\prime} \text { clock }-8 \mathrm{O}^{\prime} \\
\text { clock }\end{array}$ & $1 \mathrm{O}^{\prime}$ clock \\
\hline $\begin{array}{l}\text { Mandibular right posterior } \\
\text { teeth }\end{array}$ & $11 \mathrm{O}^{\prime}$ clock & $\begin{array}{l}4 \mathrm{O}^{\prime} \text { clock }-5 \mathrm{O}^{\prime} \\
\text { clock }\end{array}$ \\
\hline
\end{tabular}

- Chair and Patient's Position (Table 13.7).

- Operator's Position (Table 13.8) (Figs. 13.16 and 13.17).

\subsubsection{Exodontia Procedure}

Choosing the correct technique and following fundamental principles, leading to an atraumatic extraction. The three fundamental requirements for a good extraction are:

(a) Adequate access and visualization of the surgical field.

(b) An unimpeded pathway for the removal of the tooth, and

(c) Use of controlled force to luxate and remove the tooth.

Dental extractions are based on three mechanical properties, which are as follows:

1. Expansion of alveolar socket: The tooth itself is used as a dilating instrument to expand the alveolar socket in order to permit the removal of its harbored tooth. This is performed mainly in 'intra-alveolar exodontia' by holding the tooth firmly with a forceps and carrying out lateral movements in buccal and lingual directions (Fig. 13.18). This expansion depends on the elasticity of the bone which is maximal in young bone and decreases with age. Dilatation of socket results in microfractures in the bony 

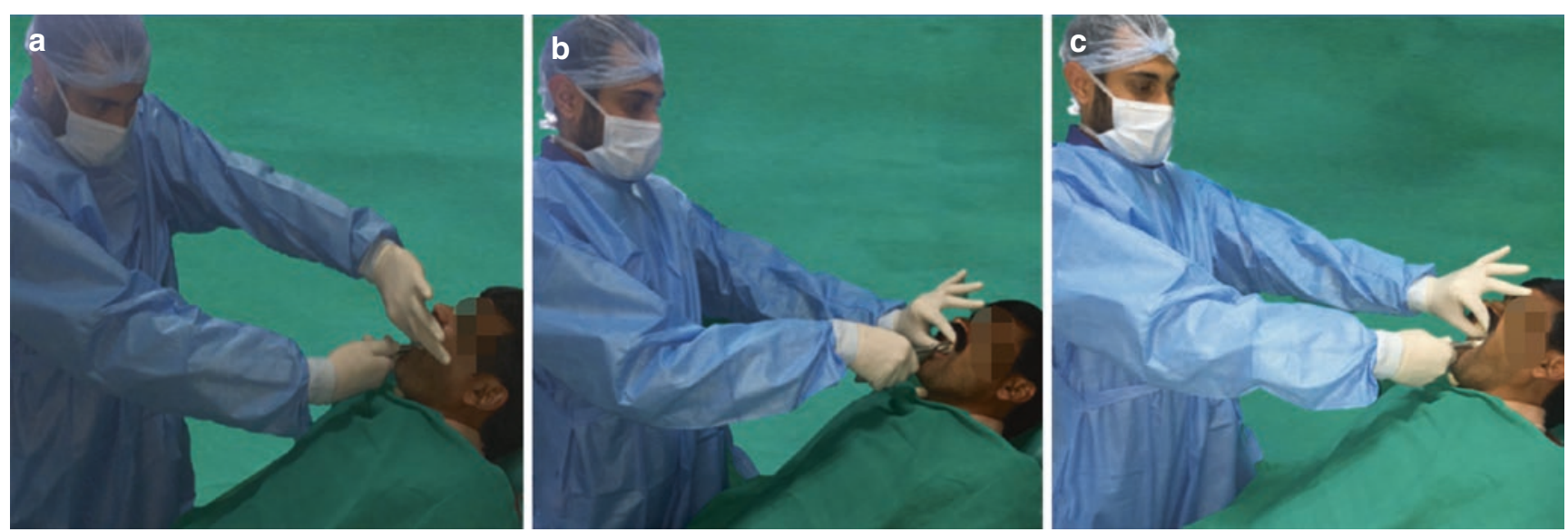

(C)Association of Oral and Maxillofacial Surgeons of India

Fig. 13.16 Operator's position for maxillary teeth extraction, (a) Right posterior, (b) Anterior, and (c) Left posterior
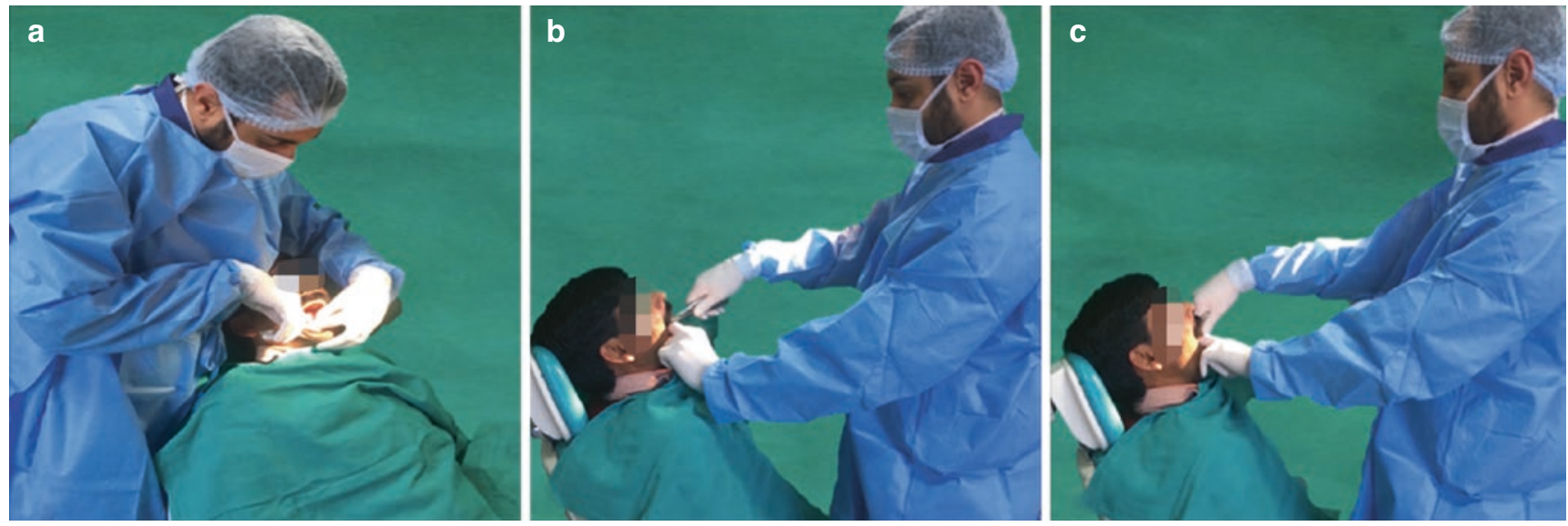

CAssociation of Oral and Maxillofacial Surgeons of India

Fig. 13.17 Operator's position for mandibular teeth extraction, (a) Right posterior, (b) Anterior, and (c) Left posterior

wall and interradicular septa. The bony fragments retain the periosteal attachment in almost all the cases and hence must be digitally compressed unless an implant placement is planned.

2. Use of Lever and Fulcrum: This principle is used to luxate the tooth or root and force it out of the socket along the path of least resistance. This principle is the basic factor which governs the use of elevators to extract tooth or tooth root (Fig. 13.14b).

3. Insertion of a wedge of wedges: Insertion of wedge between the tooth/root and bony socket wall leads to the rise of tooth in the socket (Fig. 13.19). Lesser the elasticity of bone, more are the effects of wedging. This is the reason that sometimes on application of blades of forceps, the conical rooted mandibular premolars shoot out of the sockets.
The two methods of exodontia are as follows:

1. Intra-alveolar Exodontia: This method of extraction is also referred to as closed method or routine exodontia, usually practiced for extraction of erupted and intact tooth with enough structure to grasp with a forceps and pull the tooth out of alveolar socket. Instruments used are forceps or elevators or both. This technique is the most frequently used technique for almost every extraction. However, if the operator believes that the extraction will require an excessive force or if a substantial amount of crown is missing or covered by tissue, an open technique may be opted.

5 sequential steps are to be followed for exodontia by closed technique (Fig. 13.20). Other than these 5 steps, the opposite hand also plays a vital role during the procedure which is highlighted in Table 13.9. 
Fig. 13.18 (a) Exodontia by expansion of bony socket is similar to the removal of a post embedded in the ground, (b) The post is moved laterally in a to and fro motion, (c) This results in displacement of soil surrounding the post and permitting the post to be removed out

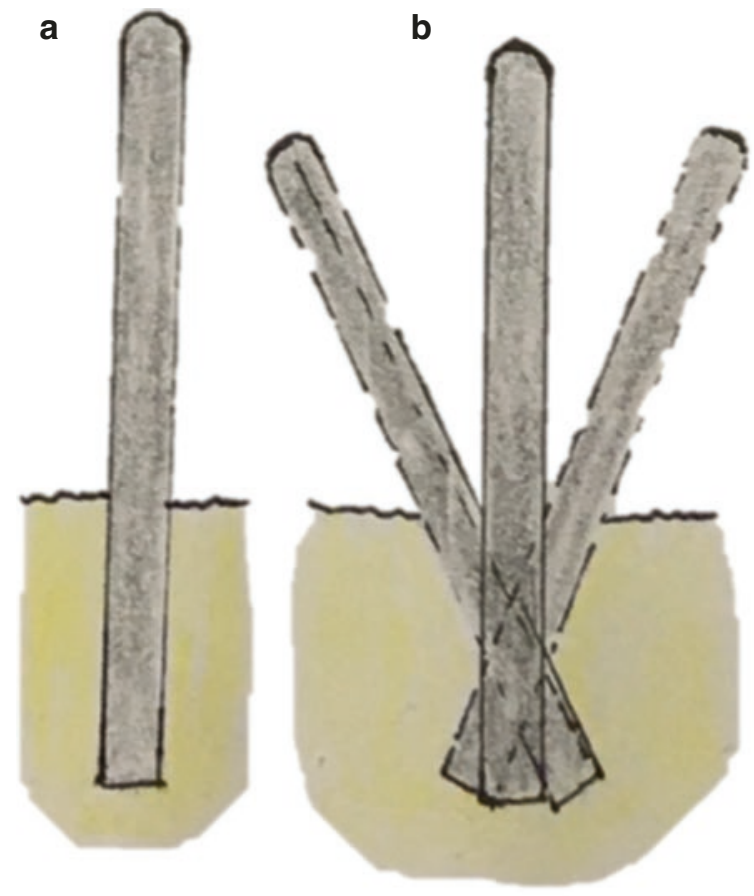

(A)Association of Oral and Maxillofacial Surgeons of India

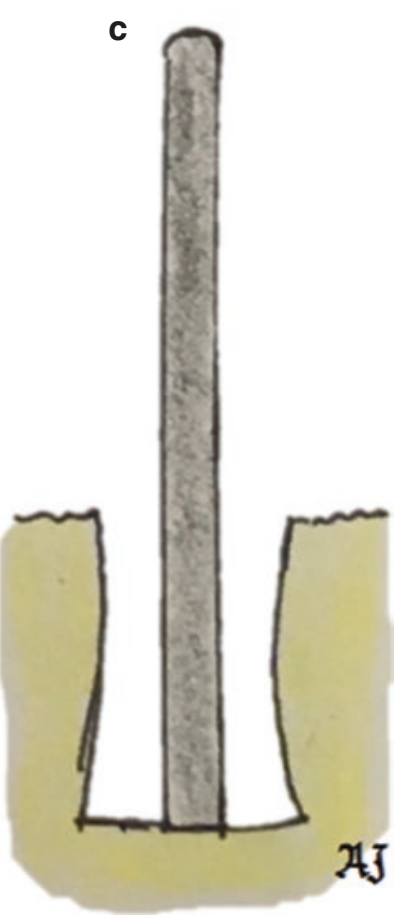

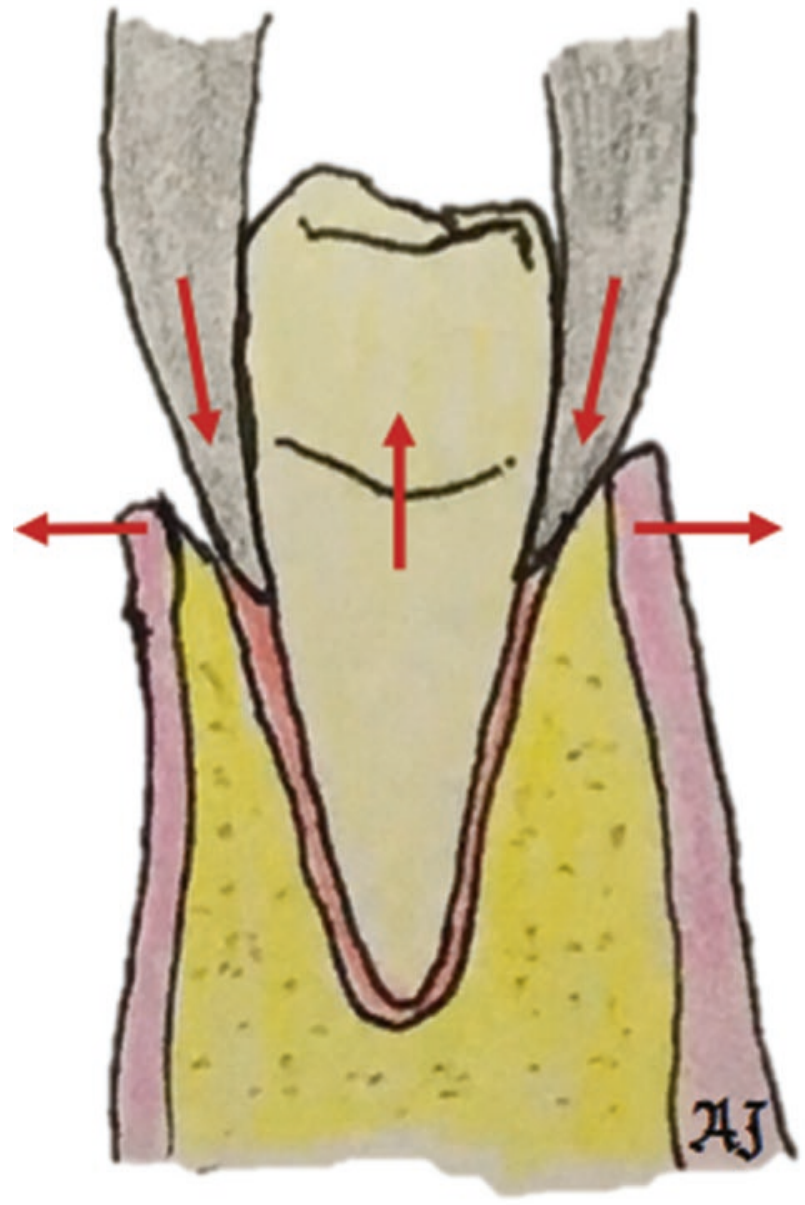

(C)Association of Oral and Maxillofacial Surgeons of India

Fig. 13.19 Insertion of wedge-shaped forceps blades resulting in rise of the tooth in the socket
2. Transalveolar Exodontia: This method includes removal of alveolar bone to access and extract the tooth. It is generally practiced for extraction of impacted teeth, root pieces, or teeth with unfavorable root form. It is often termed as surgical extraction or complicated exodontia. Indications for open technique are enlisted in Box 13.2. For an open technique exodontia, 5 steps are to be followed: (Fig. 13.23) (Clinical Case, Fig. 13.24a-f).

\subsection{Various Mucoperiosteal Flap Designs for Transalveolar Extraction}

Transalveolar exodontia necessitates incision making and subsequent mucoperiosteal flap reflection for adequate exposure of the underlying alveolar bone. The flap must be an adequate sized full-thickness mucoperiosteal flap with a broader base which is made on intact bone, avoiding injury to the local vital structures. The various types of flaps used in transalveolar exodontia are:

1. Envelope Flap: When a crevicular incision without any releasing incision is given, it produces an envelope flap. Usually, this flap provides adequate access to perform the surgery (Fig. 13.25a).

2. Triangular Flap: When a crevicular incision has one vertical releasing incision, it produces a triangular flap. It is also known as a two-sided or three-cornered flap. The three corners are posterior end of the crevicular incision, inferior 


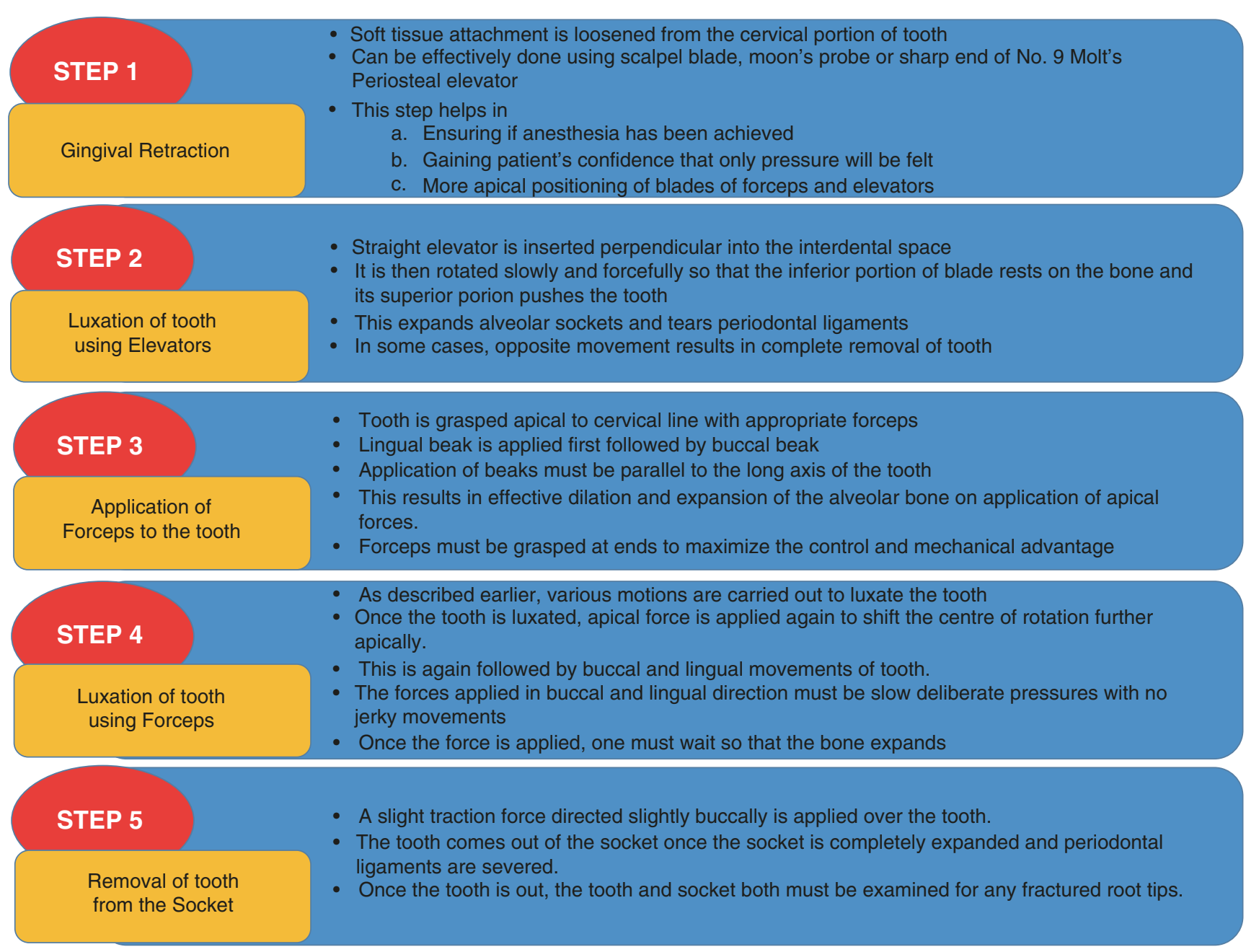

CAssociation of Oral and Maxillofacial Surgeons of India

Fig. 13.20 Steps for Intra-alveolar exodontia

Table 13.9 Role of opposite hand during exodontia

\begin{tabular}{|c|c|}
\hline Functions of opposite hand & Grasp of opposite hand \\
\hline $\begin{array}{l}\text { - Reflection of soft tissues } \\
\text { of the cheeks, lips, and } \\
\text { tongue } \\
\text { - Protection of other teeth } \\
\text { from the forceps } \\
\text { - Stabilization of patient's } \\
\text { head (along with opposite } \\
\text { arm) } \\
\text { - Supporting the jaw during } \\
\text { mandibular extraction } \\
\text { - Supporting the alveolar } \\
\text { process providing tactile } \\
\text { information regarding } \\
\text { expansion }\end{array}$ & $\begin{array}{l}\text { - Pinch grasp: While extracting } \\
\text { maxillary teeth, the operator grasps } \\
\text { the alveolar bone around the tooth } \\
\text { to be extracted by a pinch grasp } \\
\text { (Fig. 13.21) } \\
\text { - Sling grasp: While extracting } \\
\text { mandibular teeth, the operator } \\
\text { grasps the alveolar bone around the } \\
\text { tooth to be extracted by a sling } \\
\text { grasp (Fig. 13.22) }\end{array}$ \\
\hline
\end{tabular}

aspect of vertical releasing incision, and the superior aspect of the vertical releasing incision. When a greater exposure is required, this flap is preferred (Fig. 13.25b).

3. Trapezoidal Flap: When a crevicular incision has two vertical releasing incisions on either sides, it produces a trapezoidal flap. It is also known as a three-sided or fourcornered flap. Two corners are at the superior aspect of the releasing incisions and the other two corners are at the ends of the crevicular incision. The vertical releasing incisions are not vertically placed but are directed obliquely to allow a broader base (Fig. 13.25c).

Transalveolar or complicated exodontia can be further described in two types.

\section{Complicated Exodontia of Single rooted tooth.}

It starts by incision making and reflecting a sufficiently large flap to provide adequate visualization and access. Mostly an envelope flap is preferred which is extended at least two teeth anterior and one tooth posterior to the tooth that has to be extracted. If required, a releasing incision can be placed. Once the flap is reflected adequately and the surgical site is exposed sufficiently, extraction of the tooth/ root must be performed by using one of the various options. 

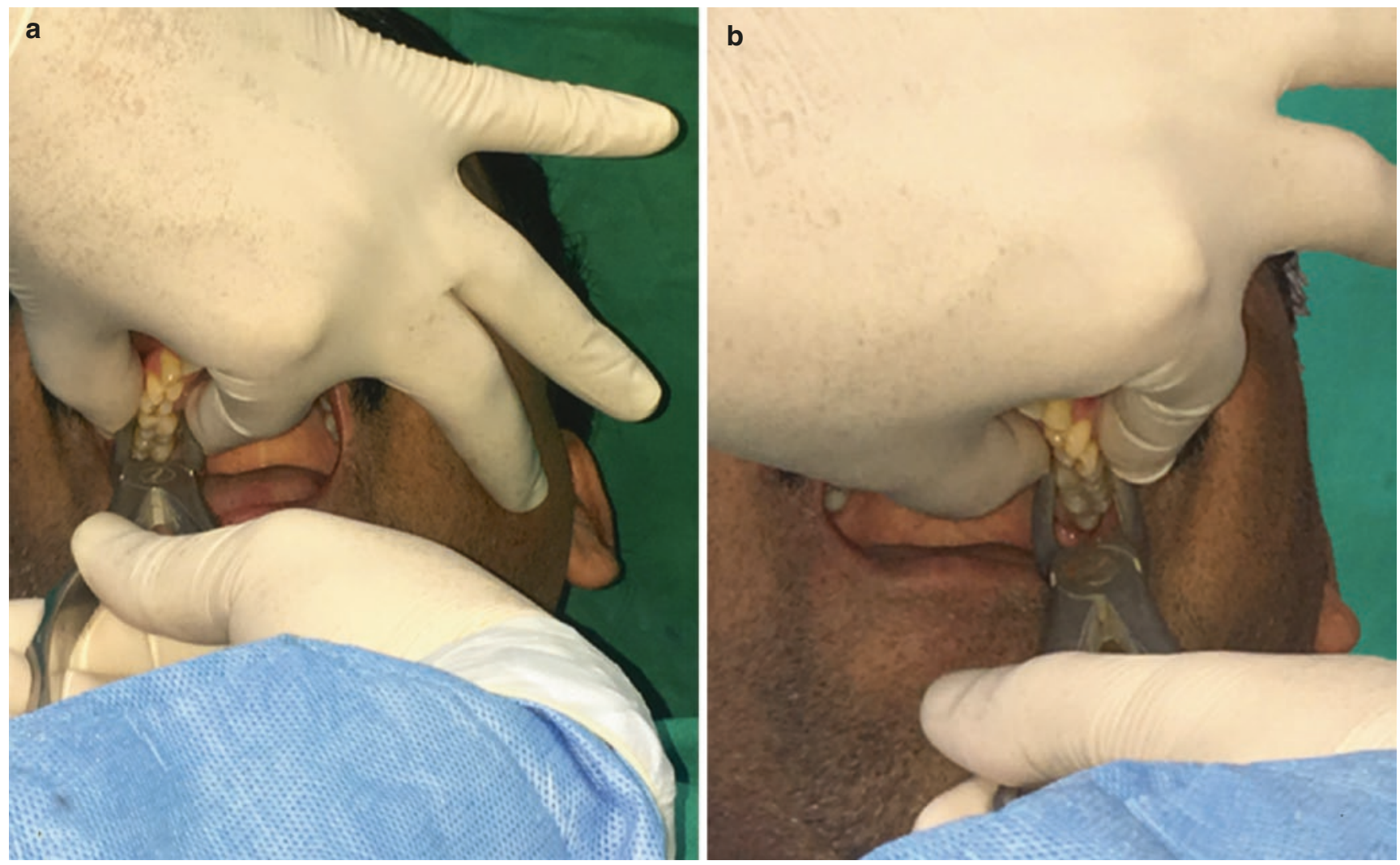

CAssociation of Oral and Maxillofacial Surgeons of India

Fig. 13.21 Pinch grasp for maxillary teeth (a) Right posterior, (b) Left posterior
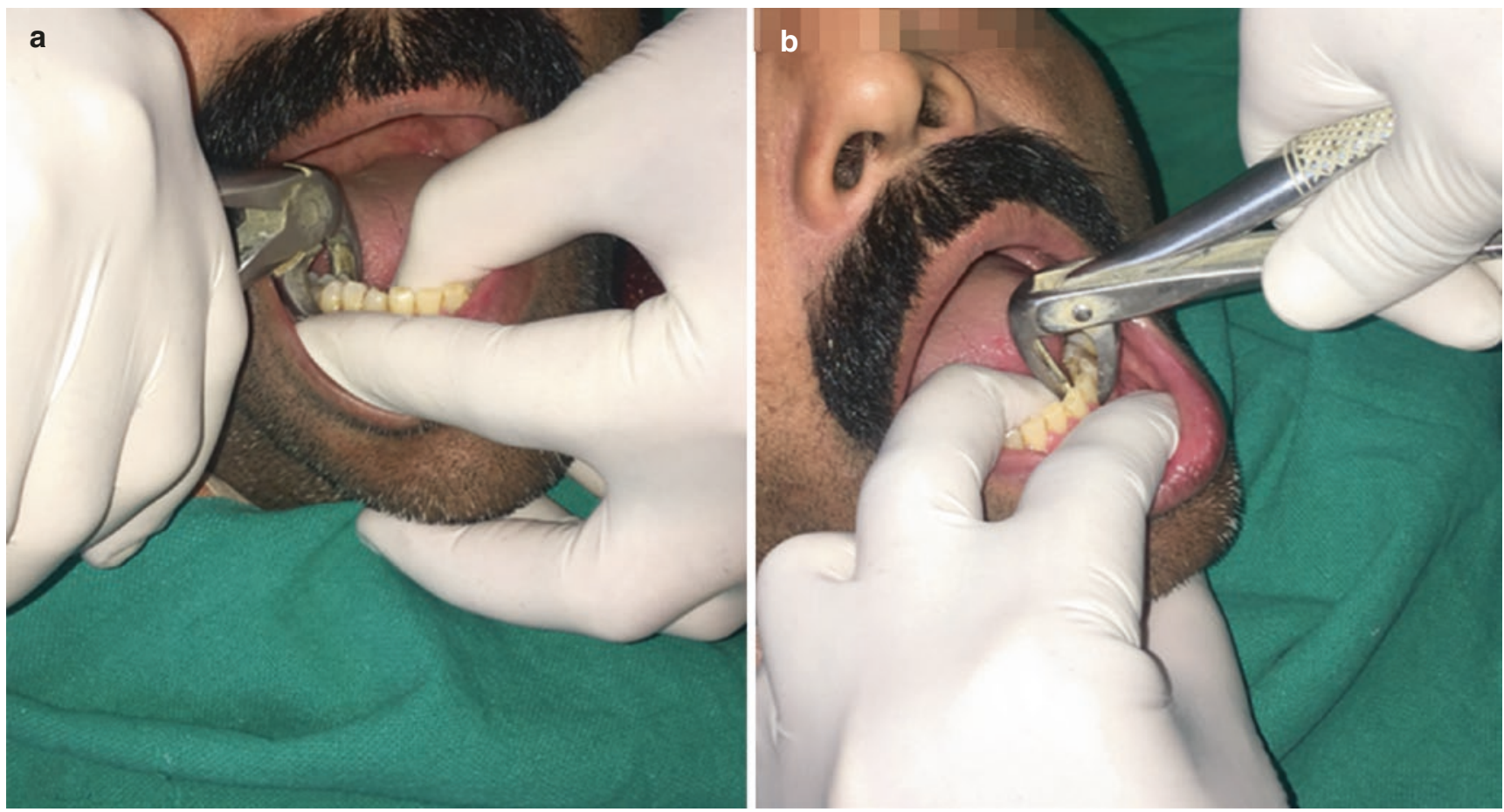

CAssociation of Oral and Maxillofacial Surgeons of India

Fig. 13.22 Sling grasp for mandibular teeth (a) Right posterior, (b) Anterior 
(a) First option is to reseat the extraction forceps under direct visualization achieving a better mechanical advantage and removing the tooth without removing any bone.

(b) Second option is to grasp a bit of buccal bone along with the root in order to obtain a better mechanical advantage. In this case, a small amount of buccal bone is pinched off and removed along with the tooth (Fig. 13.26a).

\section{Indications of Trans alveolar exodontia}

- Teeth with Severely undermined crown

- Fractured teeth

- Endodontically treated teeth

- Root pieces

- Teeth with unfavourable root form like bulbous or dilacerated roots

- Multiple divergent roots

- Ankylosed teeth

- Hypercementosis

- Presence of dense bone

- Malposed tooth

- Impacted tooth

- Tooth in proximity to vital structures

- Long standing tooth with grossly carious crown

(CAssociation of Oral and Maxillofacial Surgeons of India

Box 13.2 Indications of transalveolar exodontia (c) Third option is to push the tooth out of the socket by inserting a straight elevator into the periodontal ligament space of the tooth. A small to and fro movement should be used to insert the straight elevator as a wedge by expanding the periodontal ligament space to displace the root in an occlusal direction (Fig. 13.26b).

(d) Fourth option is to remove the bone covering the buccal aspect of root with the help of a bur along with ample irrigation. The width of the bone to be removed must be essentially equal to the mesiodistal width of the root. Also, the amount of bone to be removed in the vertical dimension should be approximately one half or two thirds the length of the root (Fig. 13.26c). Removal of this much amount of bone minimizes the force necessary for the displacement of the root, making the procedure easier. The extraction can be carried out using forceps or elevator.

(e) In some cases, removal of the root is still difficult even after the removal of bone. In such cases, a purchase point can be made in the most apical position of the exposed root with the help of a round bur. This purchase point must be $3 \mathrm{~mm}$ in diameter and deep
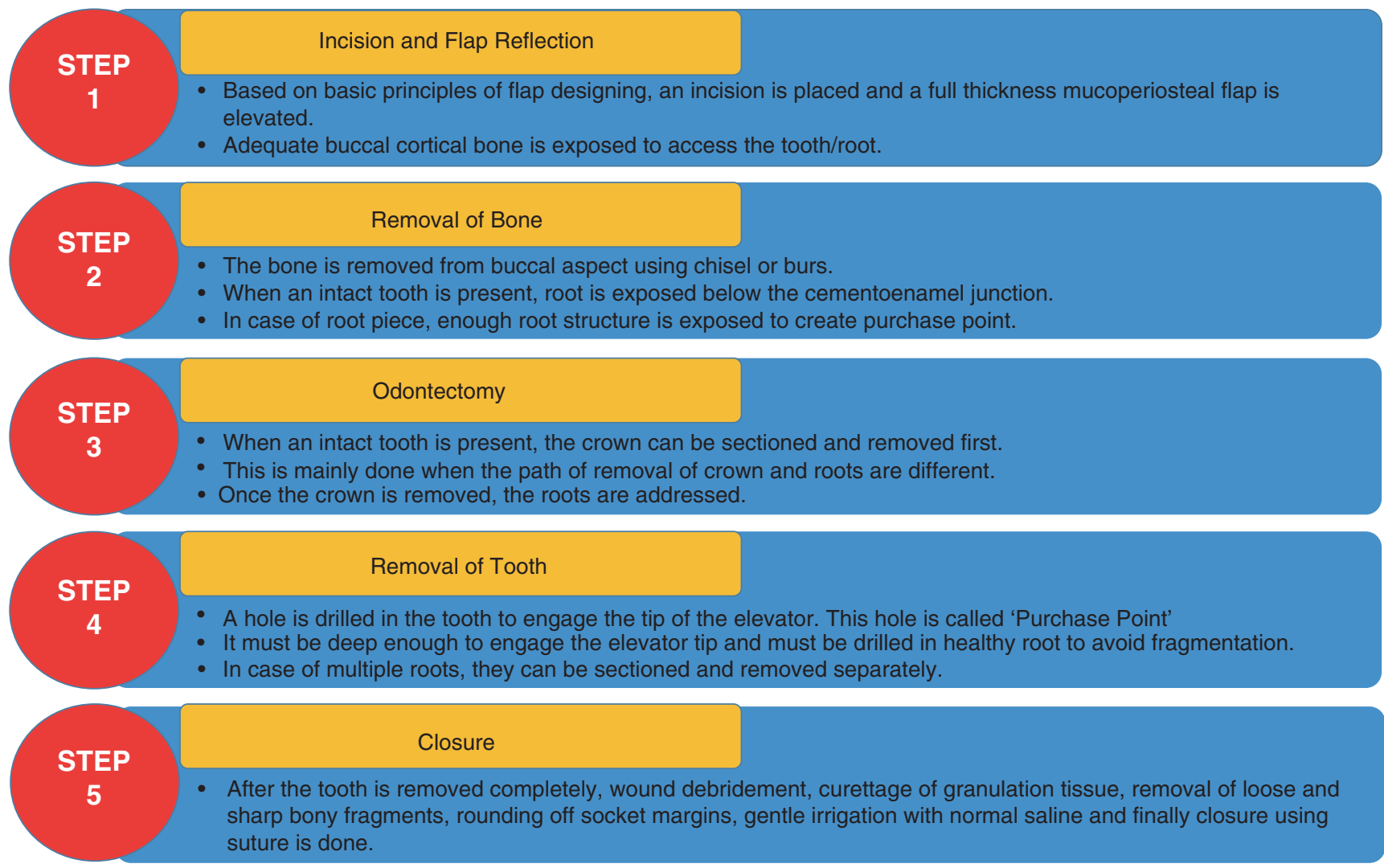

CAssociation of Oral and Maxillofacial Surgeons of India

Fig. 13.23 Steps for transalveolar exodontia 

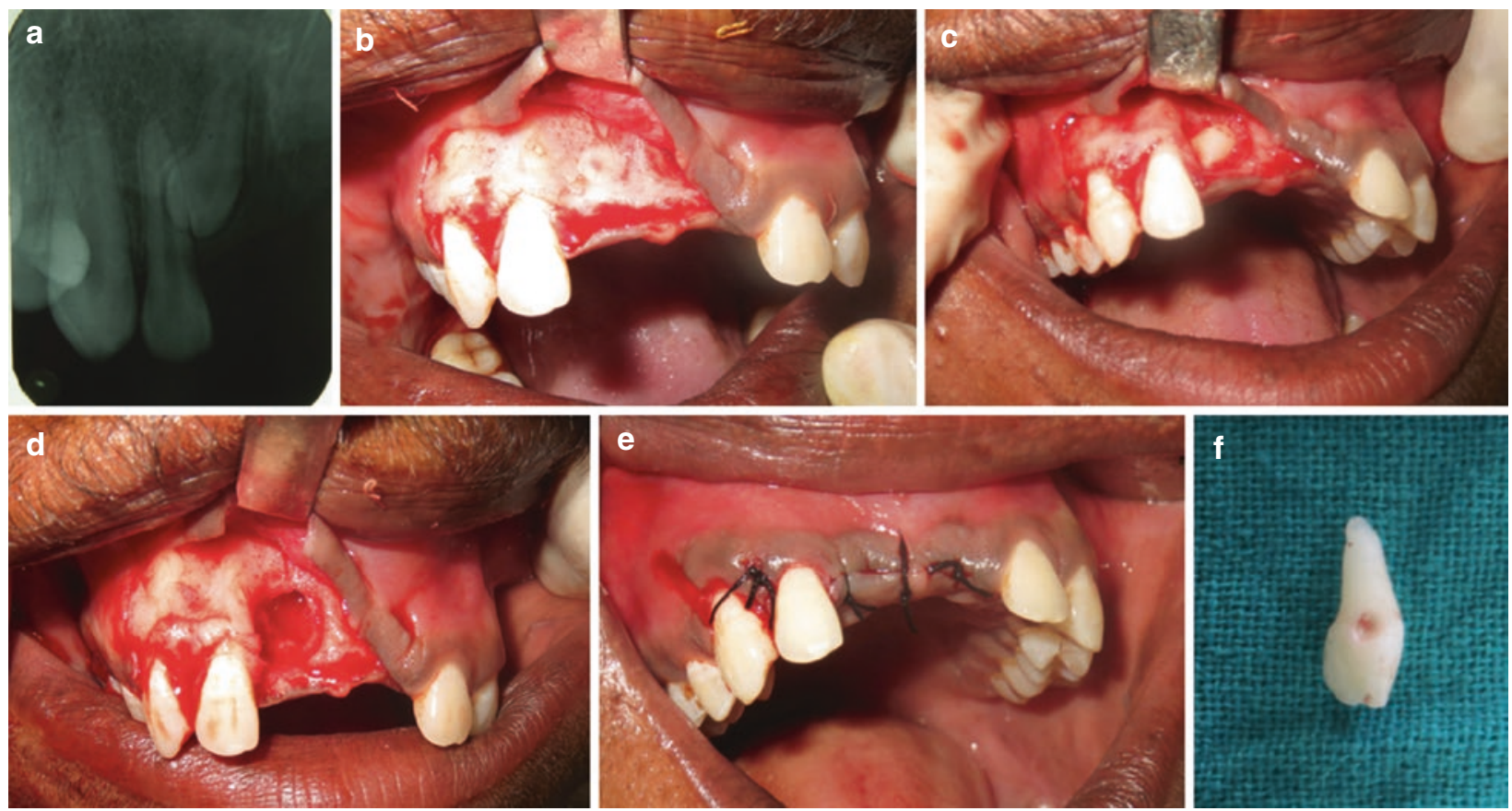

CAssociation of Oral and Maxillofacial Surgeons of India

Fig. 13.24 Transalveolar extraction of impacted tooth: (a) IOPA showing impacted tooth, (b) Incision and flap reflection (Triangular flap), (c) Bone removal, (d) Extraction socket (e) Closure, (f) Extracted tooth
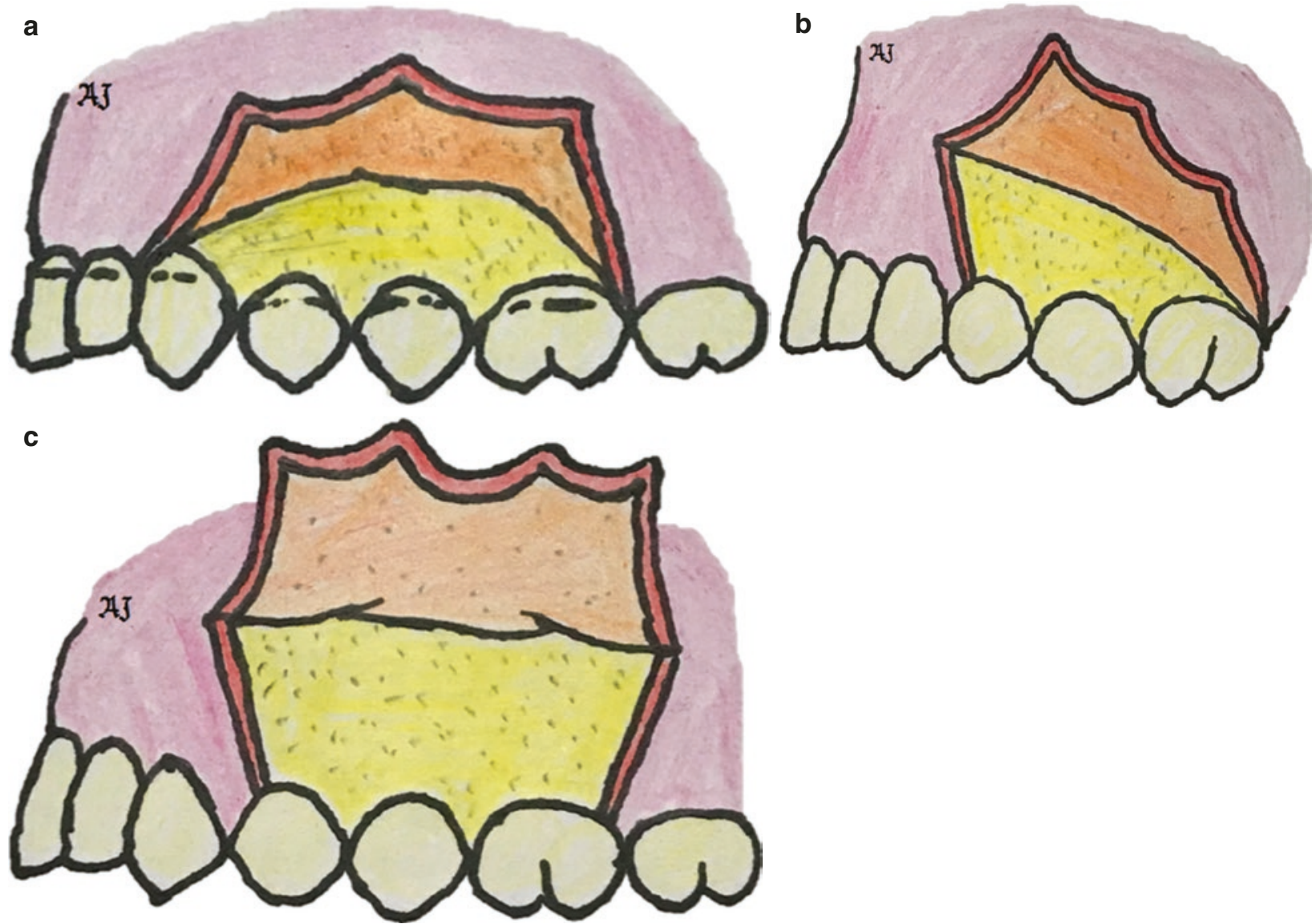

CAssociation of Oral and Maxillofacial Surgeons of India

Fig. 13.25 (a) Envelope flap, (b) Triangular flap, (c) Trapezoidal flap 
enough to engage the tip of an instrument to be used for elevation of the tooth.

Once the tooth is delivered, the sharp bony edges must be smoothened using a bone file and the whole surgical site must be thoroughly irrigated using copious amount of sterile saline. The flap must be repositioned and sutured into place.

2. Complicated exodontia of multirooted teeth.

If a treatment plan of complicated exodontia is devised for a multirooted tooth, it is extracted with the same technique as of single-rooted tooth. The only difference is that the tooth is divided using a bur to convert into two or three single-rooted fragments (odontectomy). Following incision and flap reflection, once the tooth is converted into multiple single-rooted fragments, the extraction procedure is carried out in a similar way as of single-rooted tooth. Also, the immediate postoperative procedures like smoothening of bony fragments, irrigation, and closure also remains the same. The following text describes different techniques of splitting a multirooted tooth in different scenarios.

(a) Mandibular molar with intact crown: First step involves the exposure of bifurcation by removing a small amount of crestal bone. The tooth is usually sectioned buccolingually to split the tooth into mesial and distal halves (Fig. 13.27a). These halves are then mobilized using a straight elevator and are treated as two single-rooted teeth. These teeth are then extracted with the help of mandibular premolar forceps.

Alternatively, mesial root is sectioned using a bur to convert the molar into single-rooted tooth (Fig. 13.27b). The tooth along with distal root is removed with the help of forceps followed by the removal of mesial root. This mesial root is extracted with the help of a Cryer elevator.

(b) Mandibular molar with lost crown: The roots are separated in a buccolingual direction with the help of a bur in two separate mesial and distal roots (Fig. 13.27c). A small straight elevator is inserted in between the roots and rotated to mobilize the roots and elevate the mesial root. With the help of the Cryer elevator, the mesial root is delivered out of the socket by engaging the tip into the created purchase point and rotating in a wheel-and-axle manner. The distal root is then extracted by inserting the opposite member of the Cryer instrument into the empty socket and rotating again in a wheel-and-axle manner through the interradicular bone.

(c) Maxillary molar with an intact crown: The roots of maxillary molar are three in number and are divergent. Sometimes, an open technique of extraction causes less morbidity than the closed technique as the extraction of maxillary molar requires excessive force during forceps' extraction. Once the flap is raised, a small amount of crestal bone is removed to expose the trifurcation. With the help of a straight bur, the mesiobuccal and distobuccal roots are sectioned horizontally at the level of trifurcation. This separates the two buccal roots converting the molar into single-rooted tooth (Fig. 13.27d). The molar with palatal root is then extracted using the maxillary molar forceps with gentle but firm bucco-occlusal forces. The two buccal roots are then mobilized with the help of a straight elevator. These roots are then delivered out with the help of a straight or Cryer elevator. The operator must take precaution to maintain controlled force in an apical direction during removal of these roots using the straight elevator as maxillary sinus might be in a close proximity to these roots. Uncontrolled and excessive force may result in an oroantral communication or displacement of the root into the sinus.

(d) Maxillary molar with lost crown: A small amount of buccal bone is removed to expose the roots and is divided into two buccal and palatal roots (Fig. 13.27e). The roots are mobilized with the help of a straight elevator and are extracted with the help of bayonet forceps or Cryer elevators. Generally, buccal roots are approached first followed by palatal root.

During exodontia, once completed either by closed technique or by open technique, a few important things must be kept in mind which are listed in Box 13.3 and the patient should be instructed properly as listed in Box 13.4. During exodontia, either closed or open, an assistant may be really helpful and plays an important role during the procedure (Box 13.5).

\subsection{Multiple Extractions}

If multiple adjacent teeth are indicated for extraction, a few key points are to be taken into consideration.

1. Soft tissue must be reflected to expose the crestal bone around all the teeth in the quadrant.

2. If removal of any tooth requires excessive force, a small amount of buccal bone should be removed to prevent fracture and excessive bone loss.

3. All the teeth must be luxated well enough before extraction. 

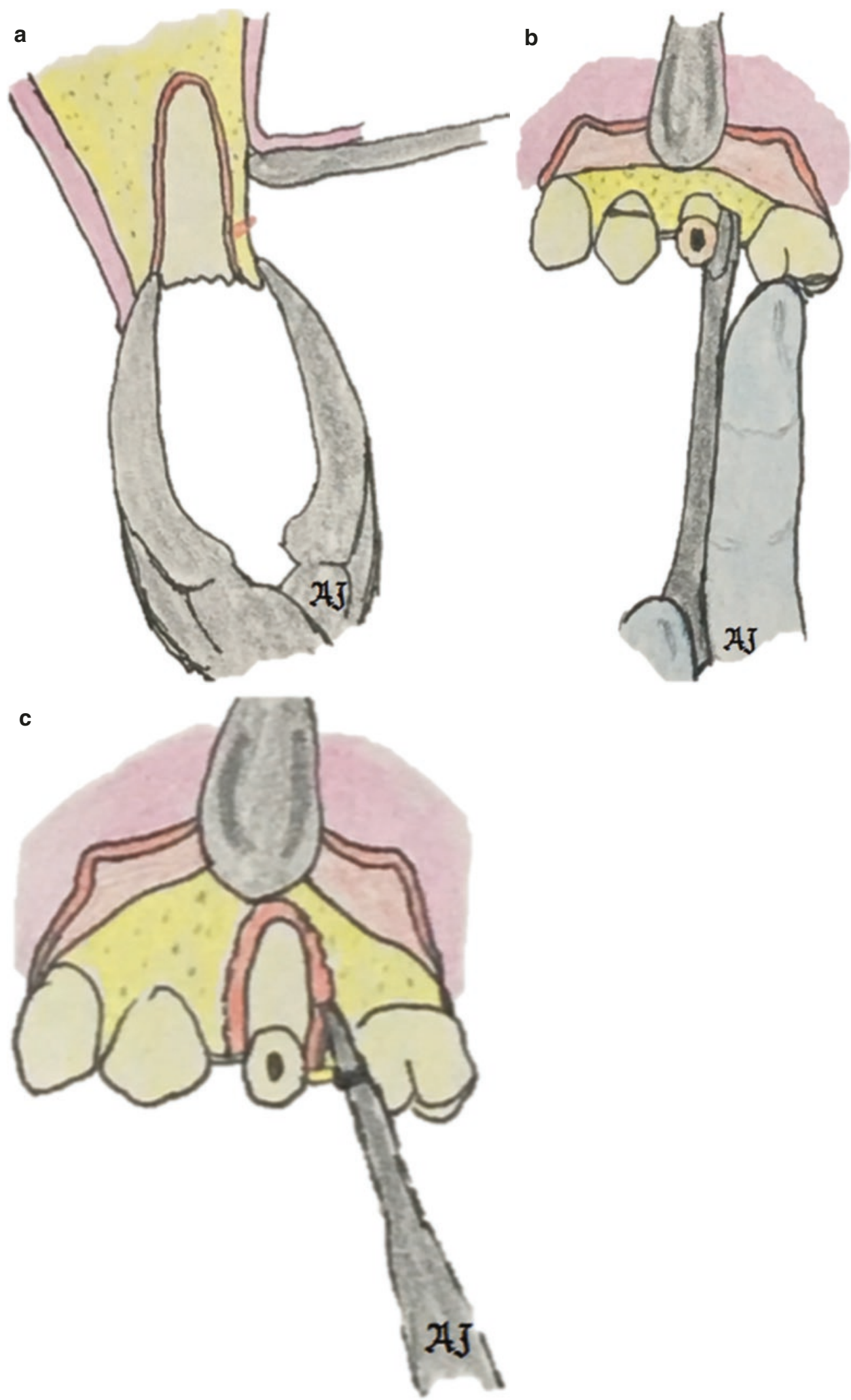

(C)Association of Oral and Maxillofacial Surgeons of India

Fig. 13.26 (a) A small portion of buccal bone is grasped along with the root in cases when the root is fractured at the level of alveolar bone (Alveolar Purchase Technique), (b) A small straight elevator is being used to luxate the broken root, (c) Bone is removed from the buccal aspect of the root using a bur 

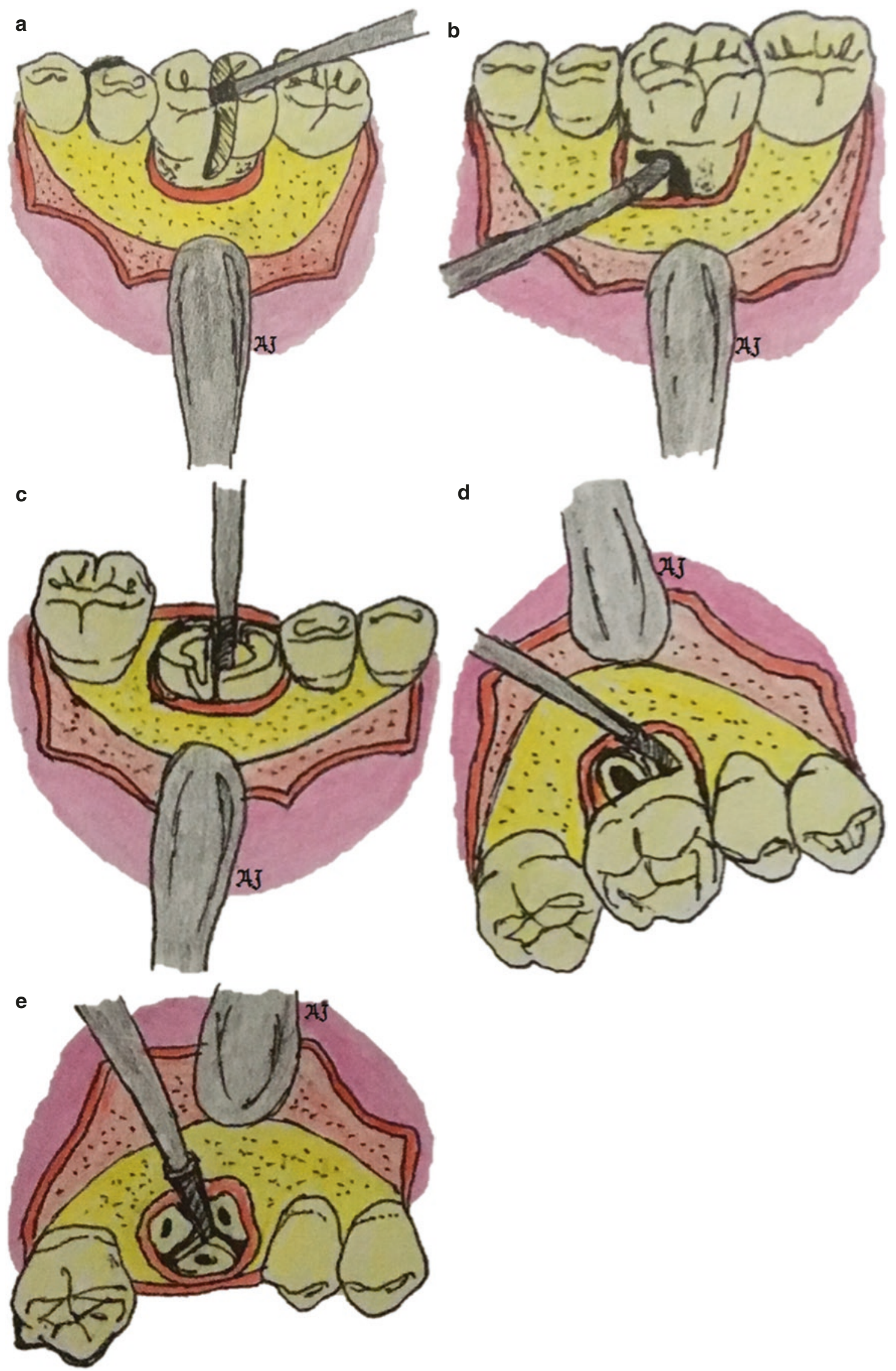

CAssociation of Oral and Maxillofacial Surgeons of India

Fig. 13.27 (a) Sectioning of tooth into mesial and distal halves, (b) Separation of mesial root from the tooth, (c) Separation of roots of mandibular molar, (d) Buccal roots are sectioned from the tooth, (e) Separation of roots of maxillary molar 
Box 13.3 Immediate post-extraction care

\section{Immediate Post -extraction Care}

Inspect the tooth and root to ensure complete removal

- Visualize the socket by thoroughly drying the socket and the adjacent field

- Inspect the socket for excessive bleeding which could be due to injured vessel (forceful bleeding) or friable granulation tissue (steadily flowing blood) and curette the socket

- Inspect for foreign bodies like fragments of tooth, calculus tags, granulation tissue, sharp bony fragments and remove using a mosquito artery if present

- Palpate the edges of socket to rule out any sharp bony margins. If present smoothen them using a file

- Compress the expanded socket with digital pressure (simple alveoloplasty). Not recommended if implant is planned

- Application of pressure pack to arrest bleeding using a moistened sterile gauze rolled over cotton wool

- Loose approximating sutures are placed following extraction to stop bleeding and prevent food impaction if required.

- Analgesics can be prescribed to the patients
Box 13.4 Postoperative instructions

\section{Post-operative Instructions}

- Maintenance of pressure pack for 30-60 minutes (Initial clot is soft and friable. Clot retraction takes 30-45 minutes)

- Swallow the saliva and not to spit or rinse till 24 hours post extraction

- Soft and cold diet for 24 hours so as not to disturb the clot and for vasoconstriction

- Warm saline rinses after 24 hours to enhance healing of socket

- Avoid smoking as it may dislodge the clot and lead to bleeding

- No hot fomentation, only cold compressions in the immediate post-operative phase

(C)Association of Oral and Maxillofacial Surgeons of India
4. Maxillary teeth are extracted first because.

(a) Infiltration anesthesia has a more rapid onset in maxilla leading to early start of the procedure.

(b) Profound anesthesia is lost early in maxilla.

(c) If mandibular teeth are extracted first, debris such as fractured crowns, bone chips, and portions of restorative material may fall in the empty mandibular sockets during extraction of maxillary teeth.

5. Hemostasis must be achieved with maxillary sockets before the extraction of mandibular teeth as the hemorrhage may interfere with mandibular surgery.

6. Extraction should be started with the most posterior teeth as it allows the effective use of dental elevators to luxate and mobilize the teeth.

7. While extracting multiple mandibular anterior teeth, an elevator is inserted between the two adjacent teeth and is rotated. This movement luxates both the teeth simultaneously aiding in the extraction of both the teeth. This technique is known as Stobies technique.

8. Canine is the most difficult tooth to extract, hence it should be extracted last.

\section{Role of Assistant during Exodontia}

- Helping surgeon to visualize or gain access to the surgical site

- Suction away blood, saliva and irrigating solutions

- Helps in protecting the teeth of opposite side

- Stabilize the head of the patient

- Support the jaw of the patient

- Psychological and Emotional support for the patient

CAssociation of Oral and Maxillofacial Surgeons of India

Box 13.5 Role of assistant

9. If maxillary and mandibular teeth of one side are to be extracted in one sitting, the sequence of extraction recommended is: Maxillary Posterior Teeth - Maxillary Anterior Teeth - Maxillary Canine - Mandibular Posterior Teeth - Mandibular Anterior Teeth Mandibular Canine.

10. Post-extraction, the buccal and lingual plates are repositioned to the original position using digital pressure unless implants are planned. 
11. If removable partial or complete dentures are planned, the undercuts and bony spicules must be identified and primary alveoloplasty must be carried out.

12. Soft tissue must be inspected for excessive granulation tissue; if present, it should be removed as it may prolong postoperative hemorrhage.

13. Papillae should be sutured in position. Primary closure must not be performed at the cost of vestibular depth, because if the vestibular depth decreases, it may interfere with denture construction.

\subsection{Extraction of Root Fragments and Tips}

Ideally, when the apical one-third of the root $(3-4 \mathrm{~mm})$ is fractured, it should be removed as it may act as a septic focus or may result in the formation of cyst or other pathologies. To extract these root tips, the two most important requirements are excellent light and excellent suction with a tip of small diameter.

Once the fracture of root tip has been diagnosed, the operator must reposition the patient to achieve proper visualization and suction. Initially, closed technique must be attempted; if unsuccessful, then the open technique must be carried out for retrieval of root tip.

- Initial attempt of root tip removal must be made by vigorous irrigation of the socket using normal saline. Following irrigation and suction, the socket must be inspected properly to check if the root has been removed or not.

- If unsuccessful, the root tip may be teased out of the socket with the help of a root tip elevator (Fig. 13.28a). The blade of the elevator is inserted in the periodontal ligament space and the root is teased out of the socket gently. Root tip elevator is a delicate instrument; hence excessive force must be avoided as it may result in bending or fracture of the blade. For larger fragments, a small straight elevator may also be used.

- If the closed technique is unsuccessful, the operator must shift to an open technique. A full-thickness mucoperiosteal flap is elevated and reflected to expose the buccal bone. The buccal bone is removed using a bur to expose the root fragment. The root is then delivered buccally with the help of an elevator (Fig. 13.28b). The socket is irrigated, flap is repositioned, and closure is performed.

- If the buccal bone has to be preserved, a modification of open technique can be performed. This technique is known as open window technique. In this technique, once the flap is reflected, the apical area of the root fragment is identified and a hole is drilled with the help of a bur. This exposes the root tip. An elevator is inserted through this hole and the root fragment is guided out of the socket (Fig. 13.28c and d).

However, if the risk during retrieval of root fragment is comparatively more than the benefit of its removal, it is advisable to leave the root in situ. If the surgeon decides to retain the root, it should be documented and informed to the patient. The criteria for retaining the root are highlighted in Box 13.6. The policy of dealing with fractured apical root tips of maxillary molars and the management of root tips displaced into the antrum is elaborated in Chap. 24 of this book.

\subsection{Extraction During Menstruation}

If permissible, extractions should be avoided during menstruation because during this period there is a high level of estrogen circulating in the blood streams which results in increased tissue bleeding. Menstrual cycle could be a determinant risk factor for alveolar osteitis. Also, both exodontia and menstruation are stressful conditions, it is better not to subject the patient to increased stresses [12].

\subsection{Extraction During Pregnancy}

Pregnancy: Second trimester is considered to be relatively safer for carrying out minor oral surgeries. However, in other trimesters, if the potential risk of retaining the tooth outweighs the complications of performing the surgery, one must plan to carry out extraction with the utmost care and avoiding use of drugs and radiographs as much as possible. Caution should be exercised to evaluate teratogenic potential of drugs when prescriptions are warranted.

During first trimester, the fetus is at risk of developmental defects if the extraction is carried out as it undergoes organogenesis. The best course of action is to prevent the patient from all kinds of infection. During the third trimester, there are chances of premature labor or even an abortion. However, if an exodontia is planned, the patient must be kept in a left lateral position. If the patient is maintained in a supine position, there are chances of obstruction of venous return resulting in supine hypotension syndrome $[13,14]$.

\subsection{Healing of Extraction Socket [15]}

Along with understanding the general principles of exodontia, it is pivotal for a dental surgeon to thoroughly know the phenomenon of healing of extraction wounds. An extraction socket heals in a similar fashion as any other wound in the body except for minor variations which occur due to the anatomic structures in and around the socket. 

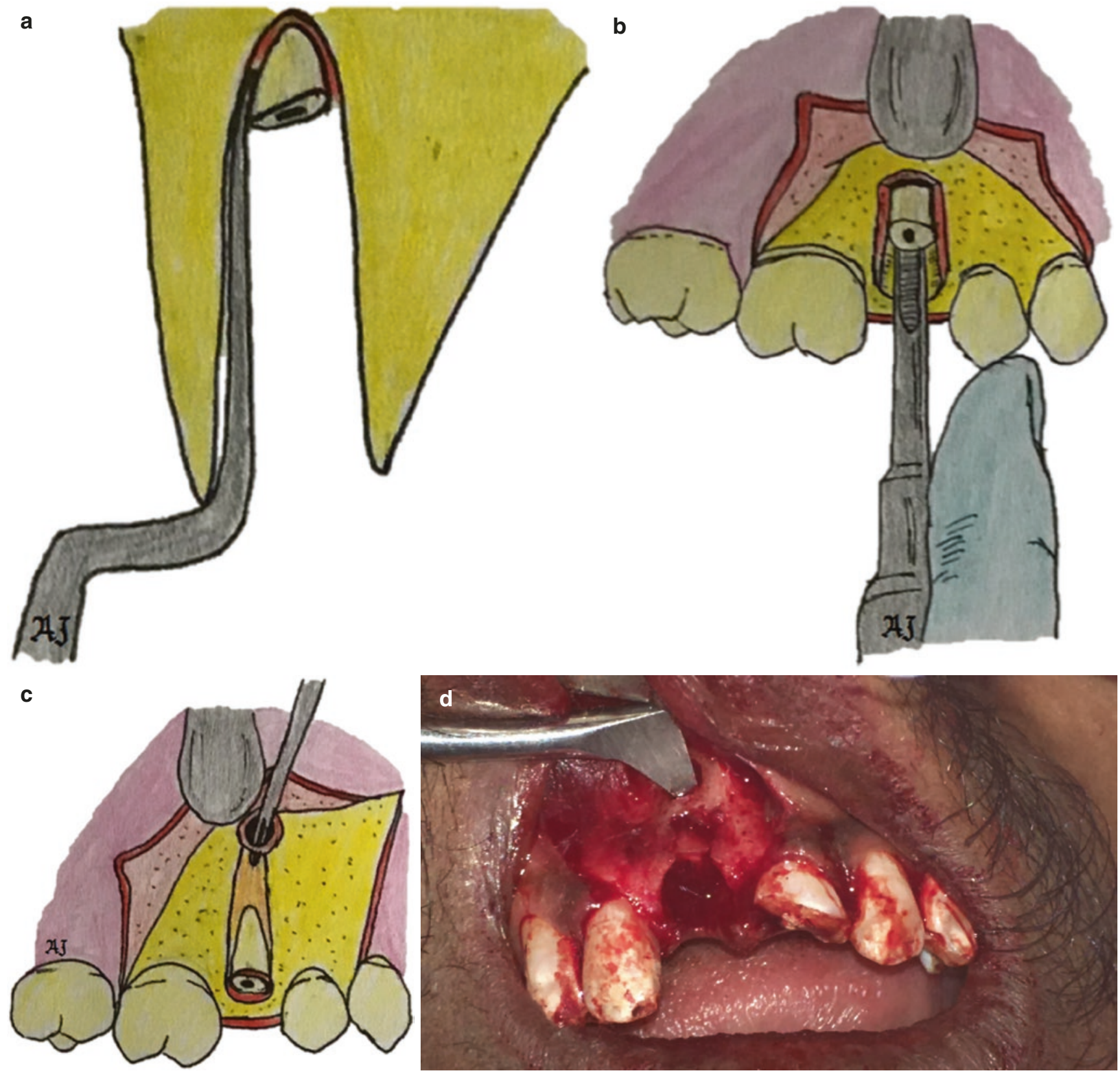

CAssociation of Oral and Maxillofacial Surgeons of India

Fig. 13.28 (a) The root tip elevator is inserted into the periodontal ligament space to elevate the root tip, (b) Open technique for removal of fractured root fragment, (c) Open Window technique for removal of fractured root fragment, (d) Clinical picture of open window technique

Box 13.6 Criteria for retaining root piece

\section{Criteria for leaving root piece in situ}

- If it is small $(<2-3 \mathrm{~mm}$ in length)

- If it is deep seated

- If it requires excessive bone removal

- If it is not infected

- If there is no presence of periapical infection

- If it is in close proximity to vital structures which may be injured during retrieval

- If during exploration there are chances of its displacement to adjacent anatomical spaces.

CAssociation of Oral and Maxillofacial Surgeons of India 
Blood present in the socket immediately after extraction of tooth coagulates and red blood cells become entrapped in the fibrin meshwork. This initial time period postextraction is critical because if the clot dislodges, healing becomes delayed and painful. Alterations in the vascular bed such as vasodilatation along with engorgement of blood vessels of periodontal ligament and transport of leukocytes around the clot occur during first 24-48 hours. A thick layer of fibrin covers the clot which shows signs of contractions. This clot forms a scaffold over which cells associated with healing grow.

In the first week following extraction, fibroblasts from remnants of PDL begin to grow in the periphery of clot and a thick layer of leucocytes gather over the clot. Osteoclastic activity starts in the crest of alveolar ridge. Blood clot undergoes organization by fibroblast and endothelial cell proliferation, signaling the growth of small capillaries in the PDL area.

Epithelial proliferation over the surface of the clot increases during the second week of healing leading to a more organized blood clot with new capillaries in the center. Remnants of PDL undergoing degeneration are no longer visible. Margins of alveolar socket appear frayed due to osteoclastic activity. Surfaces of small wounds epithelize completely by this time.

By the third week, fibrin meshwork of the original clot is replaced by mature granulation tissue. Young trabeculae formed by osteoblasts derived from pluripotent cells of PDL form around the periphery of wound. Crest of alveolar bone appears rounded due to resorption. All kinds of wound epithelize by this stage of healing.

Wound enters the final stage of healing in the fourth week. There is deposition and resorption of bone of alveolar socket which continues for several weeks. Newly formed bone is poorly calcified; therefore, the bone after extraction becomes radiographically evident only after 6-8 weeks. Loss of crestal and buccal bone during transalveolar extractions leads to smaller alveolar ridges post healing.

\subsection{Complications of Exodontia [10]}

Surgical procedures are associated with complications and exodontia is no different. Various complications related to exodontia are highlighted in Table 13.10.

Modalities to manage hemorrhage are as follows:

- Pressure packing.

- Injecting local anesthetic solution containing vasoconstrictor.

- Curettage of granulation tissue.

- Suturing.

- Use of resorbable oxidized cellulose (Surgicel) or gelatin foam (Gelfoam).

- Mechanical obstruction using bone wax.
- Tying or coagulation of visible blood vessel.

Displacement of tooth in Antrum: Operator must be careful while extracting maxillary molars to avoid displacement of tooth/root into maxillary antrum. Excessive and uncontrolled force in the apical direction may lead to displacement of tooth/root in the maxillary sinus. If displaced, it can be retrieved by carrying out sinus exploration [16].

Displacement into adjacent spaces: Tooth/root might get displaced into adjacent anatomic spaces. If it happens, retrieval must be attempted. However, delayed retrieval can also be done as foreign body reaction aids in localization of the tooth/root [17].

Loss of tooth in pharynx: During exodontia, if the tooth is lost in pharynx, one must get a chest radiograph done to rule out aspiration. If the tooth is aspirated, bronchoscopy has to be done for retrieval of tooth [18].

Injury to Temporomandibular Joint: It is mainly due to the application of excessive forces while extracting mandibular teeth and failure to support mandible. It can be avoided by using mouth gags and supporting mandible properly. Unsupported mandible may lead to dislocation of temporomandibular joint. If occurred, it must be reduced immediately by mechanical reduction.

Table 13.10 Complications of exodontia

Complications
1. General complications
(a) Postoperative pain
(b) Hemorrhage
2. Problems with tooth being extracted
(a) Root fracture
(b) Root displacement in adjacent spaces or antrum
(c) Loss of tooth in pharynx
3. Injury to adjacent teeth
(a) Fracture or dislodgement of adjacent tooth restoration
(b) Luxation of adjacent tooth
(c) Extraction of wrong tooth

4. Injury to soft tissue
(a) Abrasion
(b) Puncture wound
(c) Tear of mucosal flap

5. Injury to osseous structure
(a) Fracture of alveolar process (Fig. 13.29)
(b) Fracture of maxillary tuberosity (Fig. 13.30)

6. Injury to adjacent structures
(a) Injury to regional nerves
(b) Injury to regional vessels
(c) Injury to Temporomandibular joint

7. Oroantral communication and fistula

8. Fracture of mandible

9. Delayed healing and infection
(a) Infection
(b) Wound dehiscence
(c) Dry socket (Fig. 13.31)
(d) Osteomyelitis 


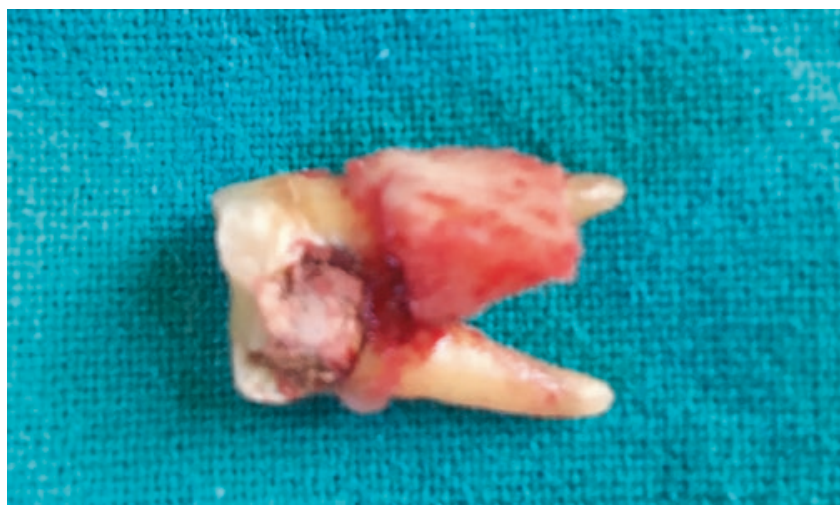

CAssociation of Oral and Maxillofacial Surgeons of India

Fig. 13.29 Fractured alveolar process

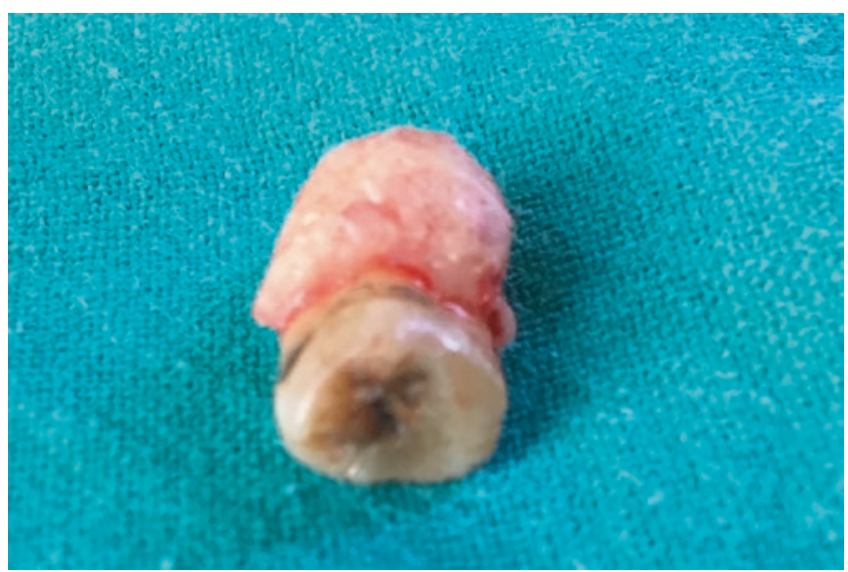

CAssociation of Oral and Maxillofacial Surgeons of India

Fig. 13.30 Fractured maxillary tuberosity

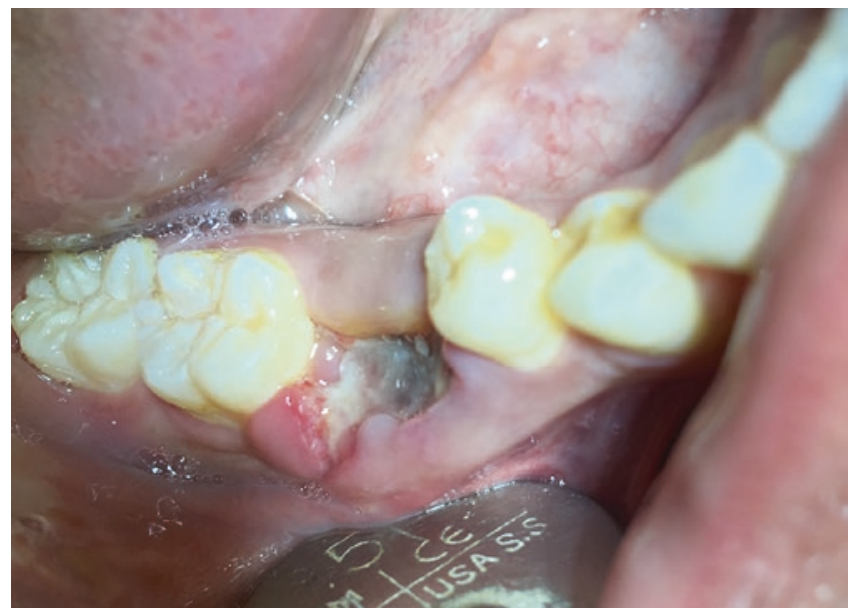

CAssociation of Oral and Maxillofacial Surgeons of India

Fig. 13.31 Dry socket
Hemorrhage: It is classified as

1. Primary hemorrhage: bleeding at the time of surgery.

2. Reactionary hemorrhage: it is seen a few hours after surgery due to cessation of vasoconstriction of damaged blood vessels.

3. Secondary hemorrhage: evident up to 14 days postoperatively due to infection.

Mechanical reduction is done by an operator standing in front of the patient and holding the mandible with both hands. The thumbs should be placed over the external oblique ridge/ molars and the fingers holding the lower border of mandible. Once held firmly, mandible should be moved in inferior, posterior, and superior directions in a sequential manner [6].

Oroantral Communication and Fistula: Oroantral communication $(\mathrm{OAC})$ is a pathologic communication between oral cavity and maxillary antrum; however, once epithelized, it is termed as oroantral fistula (OAF). OAC must be closed immediately if it is larger than $5 \mathrm{~mm}$. In cases of OAF, fistulectomy followed by closure is the treatment of choice [19].

Refer the Chap. 24 on oroantral communication and fistula for further reading.

Dry Socket: Dry socket or alveolar osteitis denotes delayed healing with moderate to severe pain. Birn's, hypothesis is the most accepted explanation of dry socket. It states that trauma and inflammation cause release of stable tissue activator from adjacent bony socket and soft tissue. Tissue activator converts plasminogen to plasmin which causes lysis of blood clot and pain. Management of dry socket involves relief of pain and ameliorating healing. A loose dressing composed of zinc oxide and oil of cloves on cotton wool is tucked into socket. Analgesic tablets and warm saline rinses are prescribed and patient is kept on regular follow-up $[20,21]$.

Osteomyelitis: It is 'an infection of the bone and the bone marrow which can be caused by an infection in the body spreading in the blood stream from point of origin to the bone'. Appropriate antibiotics for an extended period of time is the line of treatment. In chronic cases, surgical debridement becomes mandatory [22, 23].

\subsection{Technological Advances in Exodontia Techniques [24]}

Evolution never stops, this can be prominently justified by the fact that a variety of new techniques and instruments have been introduced to revolutionize the field of oral and 
maxillofacial surgery. Some of the technological advancements for dental extraction are highlighted here.

\subsubsection{Powered Periotome}

It is an electric unit which contains a controller box with adjustable power settings and a periotome mounted on a handpiece that is activated by a foot control. Use of standard periotome is cumbersome as the force delivered is uncontrolled; however, this powered periotome is characterized by complete control over the force delivery and the depth to which it travels into the periodontal ligament space.

This device functions by wedging and severing mechanisms. The thin metal blade of periotome is wedged into the periodontal ligament space in a circumferential manner severing the Sharpey's fibers. Once most of the Sharpey's fibers are severed, tooth can be extracted with minimal lateral movement. Hence, it allows flapless removal of tooth maintaining the periosteal blood supply with reduced risk of fracture of buccal or lingual cortical plate and decreased postoperative pain and discomfort.

\subsubsection{Physics Forceps (Fig. 13.32)}

Golden-Misch $[25,26]$ based on Class I lever mechanics designed the Physics Forceps to perform exodontia atraumatically. These forceps have a bumper which acts as a fulcrum, is placed at the mucogingival junction on the facial aspect applying steady, unrelenting pressure. Other than the bumper, there is a lingual beak, which is positioned on lingual or palatal root, making a single point contact with the tooth.

Due to the pressure applied by the bumper, periodontal ligament is traumatized resulting in the release of hyaluronidase. Once the enough chemical breakdown of periodontal ligament is achieved by the hyaluronidase, the tooth is released from its attachment to the alveolus aiding in easy removal. Physics forceps releases more hyaluronidase than conventional forceps in a shorter period of time, resulting in more efficient extraction of tooth with minimal trauma to the alveolar bone.

\subsubsection{Use of Implant Drills for Extraction Prior to Implant Placement}

Yalcin and colleagues [27] suggested a novel and minimally invasive technique to perform exodontia with minimal risk of damaging the thin buccal bone. The implant's drills were inserted into the root canals making the roots walls thin leading to extraction with application of much less force.

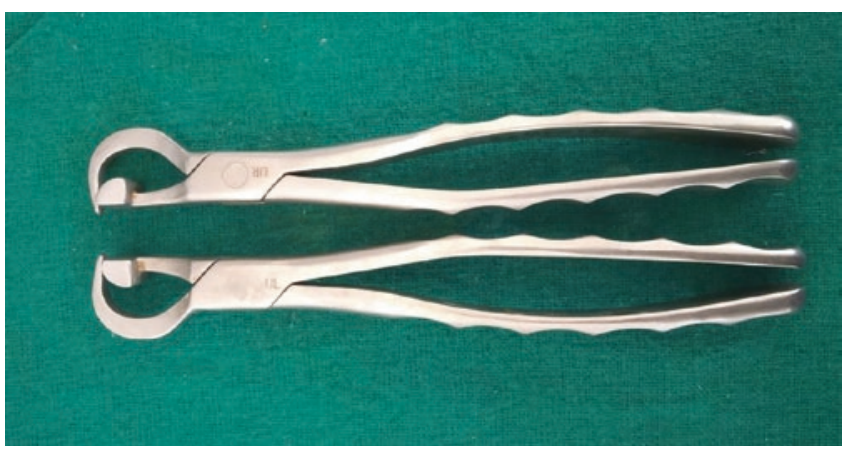

CAssociation of Oral and Maxillofacial Surgeons of India

Fig. 13.32 Physics forceps

\subsubsection{Use of LASER}

Laser offers a noncontact and low vibration bone cutting without any visible, negative, and thermal side effects. Er:YAG laser can be used for surgical extractions to ablate the covering bone layer by layer exposing the portion of the root. Once the tooth/root is uncovered, they can be conventionally removed [28]. However, laser osteotomies are time consuming and require constant suctioning to achieve a dry field for effective cutting.

\subsubsection{Piezo Surgery}

Piezo surgery is very effective in bone cutting as it works selectively without injuring any soft tissue structure. Hence, it is very advantageous over the conventional burs which have potential to cause injury to soft tissue. Also, a clearer field is obtained while using piezo surgery. However, the time required while using piezo surgery is more [29].

\subsection{CASE Scenario}

\section{CASE $1[18,30]$}

Patient is subjected to an extraction of a tooth and during the procedure, the extracted tooth is lost leaving an empty alveolar socket. The tooth is nowhere to be seen in the oral cavity neither it could be found in the surrounding area.

Possibilities:

1. Aspiration of the tooth.

2. Ingestion of the tooth.

Clinical Features:

- Aspiration.

Signs and symptom of aspiration depends on the site where the tooth is present. A laryngotracheal obstruction 
presents with dyspnea, cough, and stridor. It also results in difficulty in breathing with or without cyanosis. Chocking is also characterized by the sign of hands clutched to the throat, depending on whether the chocking is partial or complete. However, tooth in bronchus is associated with cough, diminished airway entry, dyspnea, and wheezing. Sometimes, the patient may remain asymptomatic for several months if the aspirated tooth is very small. However, long-term retention may result in late complications including postobstructive pneumonia, atelectasis, bronchiectasis, pneumothorax, hemorrhage, lung abscess, vocal cord paralysis, and death.

\section{- Ingestion.}

Generally, the passage of ingested tooth through the gastrointestinal tract is uneventful. In cases of obstruction, the most frequently noticed symptoms are dysphagia and odynophagia. Esophageal obstruction presents with gagging, coughing, chest pain, drooling of saliva, nausea, hematemesis, regurgitation, muscular incoordination, and incessant twitching. Abdominal pain is one of the symptoms other than fever, nausea, vomiting, and abdominal distensions in cases of abdominal impactions.

Management:

- Patient must be kept in a Reverse Trendelenburg position.

- If the patient has visible Airway Obstruction, he must be asked to cough and Heimlich maneuver must be attempted to relieve obstruction.

- If the object is dislodged, it should be identified and confirmed. If not, then cricothyroidectomy must be done to secure airway. If not possible in the clinic, then the patient must be rushed to the emergency unit for securing airway.

- In cases with no airway obstruction, the entire oral cavity must be examined. If the object is found, it should be identified and confirmed.

- If the object is not found in the oral cavity, the patient must be subjected to Chest radiography and Ultrasonography Abdomen.

- For radiolucent objects, bronchoscopy and Computed Tomography of Chest and Abdomen are preferred.

- If the object is in respiratory tract, bronchoscopy must be planned for retrieval.

- If the object is in Esophagus, Endoscopic removal must be done.

- If the object is in Gastrointestinal tract (GIT), beyond esophagus, patient must be monitored for 2 weeks with serial radiographs. Stool examination must be done till the object is expelled.

- If the object is retrieved, identify and confirm.

- If the object is not retrieved, radiographic examination must be repeated.
- Radiographic examination reveals the absence of object in GIT, it should be assumed that the object has passed out. The patient must be reassured, however, must be kept on follow-up.

- If the radiographic examination reveals the presence of object in GIT, the patient must be referred to a gastroenterologist for removal either by surgery or by endoscopy.

- During the whole process, the patient must be reassured time and again.

\section{CASE 2 [31]}

A 33 year-old male reported with a chief complaint of a firm, diffuse swelling of size approximately $2 \times 1 \mathrm{~cm}$ in left mandibular body region with occasional pus discharge from the extraoral skin fistula (Fig. 13.33a). He also complained of associated intermittent pain and fever.

\section{History}

On further questioning, he revealed that he had visited a private clinic 6 months back for the complaint of dental caries. Following clinical and radiographic examination, the dentist had planned to extract the tooth. To the patient's knowledge, the extraction was done uneventfully, but one root was lost during the procedure. Patient was prescribed with antibiotics and analgesics for a period of 5 days. The patient became apprehensive and uneasy in the following days. The fear of further complications kept him from visiting the dentist again and the condition went on worsening. Finally, after 6 months, he reported to an oral and maxillofacial surgeon.

\section{Investigations}

An orthopantomogram was taken which revealed a displaced root fragment in left first molar region. (Fig. 13.33b).

\section{Diagnosis}

Displacement of Mandibular molar root in buccal space.

\section{Management}

After obtaining patient's consent, under antibiotic coverage and local anesthesia, surgical exploration was done through the existing skin fistula extraorally. With the digital pressure, the root piece was delivered out (Fig. 13.33c). Curettage and debridement was done carefully and patient was kept on follow-up. Closure was not performed. Antibiotics, analgesic, and nonsteroidal anti-inflammatory drugs were prescribed postoperatively. Patient recovered without further incident. In the late period of follow-up, no complication was observed except extraoral scarring. 

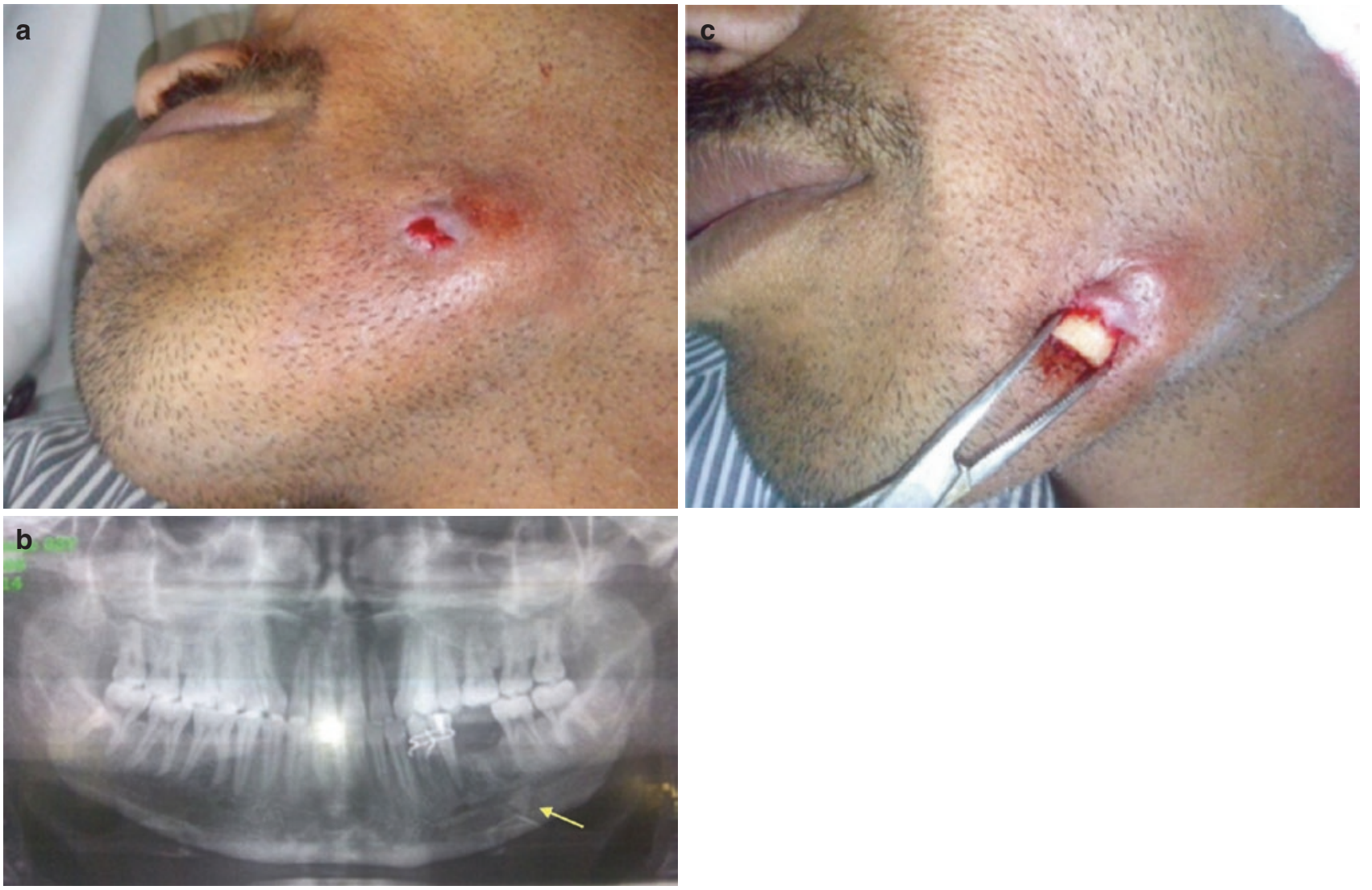

Fig. 13.33 (a) Patient with extraoral swelling and skin fistula. (b) Orthopantomogram showing displacement of left first mandibular molar root into adjacent space. (c) Retrieval of root from buccal space

\section{References}

1. Howe GL. The extraction of teeth. 2nd ed. Bristol: J Wright; 1974.

2. Bennion E. Antique dental instruments. London: Sotheby's Philip Wilson Publishers; 1986.

3. Kumar A. Dentistry in historical perspective. IJOCR. 2013;1(2): $51-4$.

4. Ring ME. Dentistry: An illustrated history. New York/St Louis, Toronto: Harry N Abrams/The CV Mosby Company; 1992.

5. Atkinson HF. Some early dental extraction instruments including the pelican, bird or axe? Aust Dent J. 2002;47(2):90-3.

6. Borle RM. Textbook of oral and maxillofacial surgery. 1st ed. New Delhi: Jaypee Brothers Medical Publishers; 2014.

7. Teja MV, Teja TS, Shetty S, Kashyap R. The rise of Indian orthodontics: a historical perspective. J Ind Orthod Soc. 2013;47(3):113-20.

8. Koga DH, Salvajoli JV, Alves FA. Dental extractions and radiotherapy in head and neck oncology: review of the literature. Oral Dis. 2008 Jan;14(1):40-4.

9. Johri A, Piecuch JF. Should teeth be extracted immediately in the presence of acute infection? Oral Maxillofac Surg Clin North Am. 2011 Nov;23(4):507-11.

10. Hupp J, Ellis E III, Tucker M. Contemporary oral and maxillofacial surgery. 6th ed. London: Elsevier, RELX; 2017.

11. Moore UJ. Principles of oral and maxillofacial surgery. 6th ed. Hoboken: Blackwell Science; 2011.

12. Eshghpour M, Rezaei NM, Nejat A. Effect of menstrual cycle on frequency of alveolar osteitis in women undergoing surgical removal of mandibular third molar: a single-blind randomized clinical trial. J Oral Maxillofac Surg. 2013 Sep;71(9):1484-9.

13. Beard RW, Roberts GM. Supine hypotension syndrome. Br Med J. 1970 May 2;2(5704):297.

14. Steinberg BJ, Hilton IV, Iida H, Samelson R. Oral health and dental care during pregnancy. Dent Clin N Am. 2013 Apr;57(2):195-210.

15. Farina R, Trombelli L. Wound healing of extraction sockets. Endod Top. 2012;25:16-43.

16. Fickling BW. Oral surgery involving the maxillary sinus. Ann R Coll Surg Engl. 1957 Jan;20(1):13-35.

17. Huang IY, Wu CW, Worthington P. The displaced lower third molar: a literature review and suggestions for management. J Oral Maxillofac Surg. 2007 Jun;65(6):1186-90.

18. Elgazzar RF, Abdelhady AI, Sadakah AA. Aspiration of an impacted lower third molar during its surgical removal under local anaesthesia. Int J Oral Maxillofac Surg. 2007;36:362-4.

19. Dym H, Wolf JC. Oroantral communication. Oral Maxillofac Surg Clin North Am. 2012 May;24(2):239-47.

20. Tarakji B, Saleh LA, Umair A, Azzeghaiby SN, Hanouneh S. Systemic review of dry socket: aetiology, treatment, and prevention. J Clin Diagn Res. 2015 Apr;9(4):ZE10-3.

21. Houston JP, McCollum J, Pietz D, Schneck D. Alveolar osteitis: a review of its etiology, prevention, and treatment modalities. Gen Dent. 2002 Sep-Oct;50(5):457-463. quiz 464-5.

22. Lorè B, Gargari M, Ventucci E, Cagioli A, Nicolai G, Calabrese L. A complication following tooth extraction: chronic suppurative osteomyelitis. Oral Implantol (Rome). 2013 Oct $15 ; 6(2): 43-7$. 
23. González-Navarro B, Arranz-Obispo C, Albuquerque R, JanéSalas E, López-López J. Osteomyelitis of the jaw (with pathological fracture) following extraction of an impacted wisdom tooth. A case report. J Stomatol Oral Maxillofac Surg. 2017 Oct;118(5): 306-9.

24. Weiss A, Stern A, Dym H. Technological advances in extraction techniques and outpatient oral surgery. Dent Clin N Am. 2011 Jul;55(3):501-13.

25. Golden RM, inventor; GoldenMisch Inc, assignee. Dental plier design with offset- ting jaw and pad elements for assisting in removing upper and lower teeth utilizing the dental plier design. US patent 6,910,890. June 28, 2005.

26. Misch C, Perez H. Atraumatic extractions: a biomechanical route. Dent Today. 2008;27:8.

27. Yalcin S, Aktas I, Emes Y, et al. A technique for atraumatic extraction of teeth before immediate implant placement. Implant Dent. 2009;18:6

28. Giovannacci I, Giunta G, Pedrazzi G, Meleti M, Manfredi M, Migliario M, Brucoli M, Greco Lucchina A, Mortellaro C, Vescovi P. Erbium yttrium-aluminum-garnet laser versus traditional bur in the extraction of impacted mandibular third molars: analysis of intra- and postoperative differences. J Craniofac Surg. 2018 Nov;29(8):2282-6.

29. Badenoch-Jones EK, David M, Lincoln T. Piezoelectric compared with conventional rotary osteotomy for the prevention of postoperative sequelae and complications after surgical extraction of mandibular third molars: a systematic review and meta-analysis. Br J Oral Maxillofac Surg. 2016 Dec;54(10):1066-79.
30. Yadav RK, Yadav HK, Chandra A, Yadav S, Verma P, Shakya VK. Accidental aspiration/ingestion of foreign bodies in dentistry: a clinical and legal perspective. Natl J Maxillofac Surg. 2015;6:144-5.

31. Jain A. Accidental displacement of mandibular first molar root into buccal space: a unique case. J Stomatol Oral Maxillofac Surg. 2018;119(5):429-31.

\section{Articles for Additional Reading}

Dym H, Weiss A. Exodontia: tips and techniques for better outcomes. Dent Clin North Am. 2012;56(1):245-66.

Araújo MG, Silva CO, Misawa M, Sukekava F. Alveolar socket healing: what can we learn? Periodontol 2000. 2015;68(1):122-34.

Nayyar J, Clarke M, O’Sullivan M, Stassen LF. Fractured root tips during dental extractions and retained root fragments. A clinical dilemma? Br Dent J. 2015;218(5):285-90.

Lodi G, Figini L, Sardella A, Carrassi A, Del Fabbro M, Furness S. Antibiotics to prevent complications following tooth extractions. Cochrane Database Syst Rev. 2012;11:CD003811.

Open Access This chapter is licensed under the terms of the Creative Commons Attribution 4.0 International License (http://creativecommons. org/licenses/by/4.0/), which permits use, sharing, adaptation, distribution and reproduction in any medium or format, as long as you give appropriate credit to the original author(s) and the source, provide a link to the Creative Commons license and indicate if changes were made.

The images or other third party material in this chapter are included in the chapter's Creative Commons license, unless indicated otherwise in a credit line to the material. If material is not included in the chapter's Creative Commons license and your intended use is not permitted by statutory regulation or exceeds the permitted use, you will need to obtain permission directly from the copyright holder. 